\title{
ALTERNATIVE FUELS AND VEHICLES CHOICE MODEL
}

\author{
David L. Greene
}

Center for Transportation Analysis

Oak Ridge National Laboratory

October 1994

Prepared by the

OAK RIDGE NATIONAL LABORATORY

Oak Ridge, Tennessee 37831

managed by

MARTIN MARIETTA ENERGY SYSTEMS, INC.

for the

U. S. DEPARTMENT OF ENERGY

under contract DE-AC05-84OR21400

NOTICE This document contains information of a preliminary nature.

It is subject to revision or correction and therefore does not represent a final report.

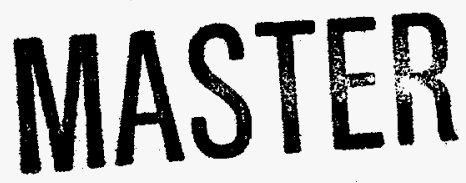





\section{DISCLAIMER}

This report was prepared as an account of work sponsored by an agency of the United States Government. Neither the United States Government nor any agency thereof, nor any of their employees, make any warranty, express or implied, or assumes any legal liability or responsibility for the accuracy, completeness, or usefulness of any information, apparatus, product, or process disclosed, or represents that its use would not infringe privately owned rights. Reference herein to any specific commercial product, process, or service by trade name, trademark, manufacturer, or otherwise does not necessarily constitute or imply its endorsement, recommendation, or favoring by the United States Government or any agency thereof. The views and opinions of authors expressed herein do not necessarily state or reflect those of the United States Government or any agency thereof. 


\section{DISCLAIMER}

Portions of this document may be illegible in electronic image products. Images are produced from the best available original document. 
TABLE OF CONTENTS

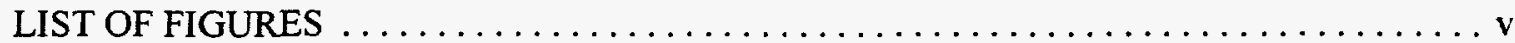

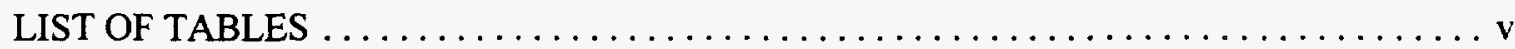

ACKNOWLEDGMENTS $\ldots \ldots \ldots \ldots \ldots \ldots \ldots \ldots \ldots \ldots \ldots \ldots \ldots \ldots \ldots \ldots \ldots \ldots \ldots$

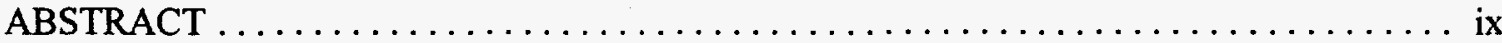

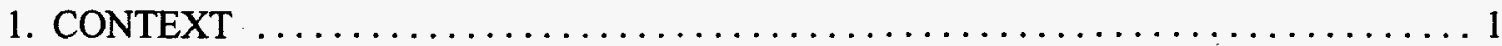

2. SPECIFICATION OF A VEHICLE AND FUEL CHOICE MODEL $\ldots \ldots \ldots \ldots \ldots \ldots 7$

2.1 HEDONIC DEMAND AND RANDOM UTILITY $\ldots \ldots \ldots \ldots \ldots \ldots \ldots \ldots \ldots$

2.2 THEORY AND MATHEMATICAL FORM OF THE AFVC MODEL $\ldots \ldots \ldots \ldots 10$

2.3 FACTORS IN THE FUEL CHOICE DECISION $\ldots \ldots \ldots \ldots \ldots \ldots \ldots \ldots \ldots \ldots$

2.4 STRATEGY FOR CALIBRATING THE AFVC MODEL $\ldots \ldots \ldots \ldots \ldots \ldots \ldots . \ldots \ldots$

3. SPECIFICATION AND VALUATION OF FUEL AND VEHICLE

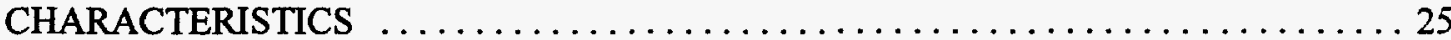

3.1 CHARACTERISTICS ASSOCIATED WITH FUEL USE $\ldots \ldots \ldots \ldots \ldots \ldots \ldots \ldots$

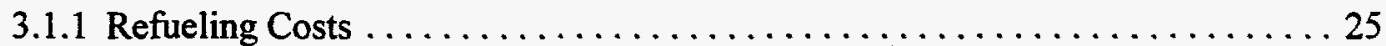

3.1.2 Fuel Option Value for Multi-Fuel Vehicles .................... 30

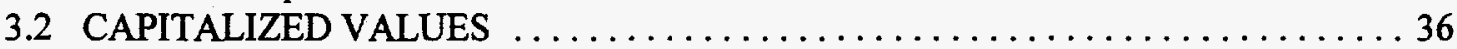

3.2.1 Estimation of Capital Costs per Barrel of Gasoline Equivalent . . . . . . . . 36

3.2.2 Incremental Costs of AFVs . . . . . . . . . . . . . . . . . . 38

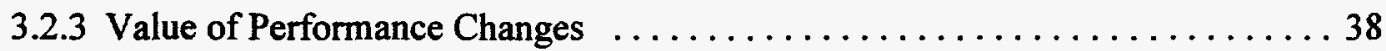

3.2 .4 Value of Cargo Capacity . . . . . . . . . . . . . . . . . 40

3.3 CALCULATION OF NMNL MODEL COEFFICIENTS $\ldots \ldots \ldots \ldots \ldots \ldots \ldots \ldots 1$

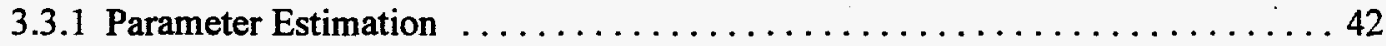

3.3.2 Estimation of Inclusive Values for Multi-Fuel and Single-Fuel Vehicles . . . . 45

4. IMPLEMENTATION OF THE ALTERNATIVE FUEL VEHICLE

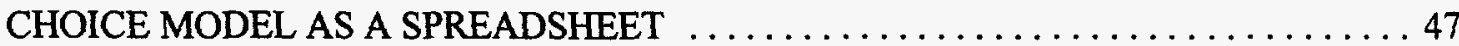

4.1 AFTM FUEL AND VEHICLE CHOICE SCENARIO $\ldots \ldots \ldots \ldots \ldots \ldots \ldots \ldots 47$

4.2 CALCULATION OF VALUE OF RANGE AND REFUELING TIME $\ldots \ldots \ldots \ldots \ldots 5$

4.3 CALCULATION OF LOST CARGO SPACE VALUE $\ldots \ldots \ldots \ldots \ldots \ldots \ldots . \ldots \ldots 2$

4.4 CALCULATION OF PERFORMANCE VALUE $\ldots \ldots \ldots \ldots \ldots \ldots \ldots \ldots \ldots \ldots . \ldots \ldots$

4.5 ALTERNATIVE FUELS OPTION VALUE CALCULATION $\ldots \ldots \ldots \ldots \ldots \ldots 57$

4.6 VEHICLE AND FUEL CHOICE MARKET SHARES CALCULATION . . . . . 58

5. SENSITIVITY OF AFVC MODEL TO KEY PARAMETERS $\ldots \ldots \ldots \ldots \ldots \ldots \ldots \ldots$

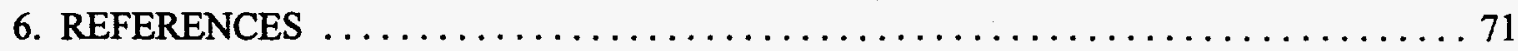

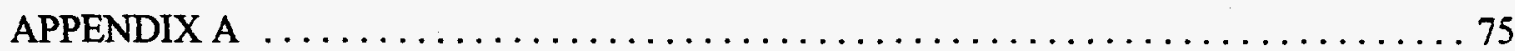




\section{LIST OF FIGURES}

Figure 1.1 Alternative Fuels and Vehicles Choice Model Flowchart of Calibration Process . . 3

Figure 2.1 Nested Structure of Alternative Fuel and Vehicle Choice Decisions . . . . . . . 11

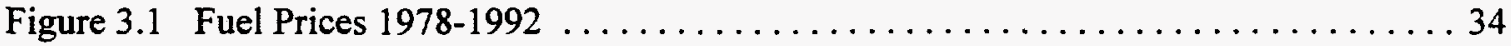

Figure 4.1 AFTM Fuel and Vehicle Choice Scenario $\ldots \ldots \ldots \ldots \ldots \ldots \ldots \ldots \ldots$

Figure 4.2 Calculation of Value of Range and Refueling Time $\ldots \ldots \ldots \ldots \ldots \ldots \ldots$. . . . 51

Figure 4.3 Calculation of Value of Lost Cargo Space $\ldots \ldots \ldots \ldots \ldots \ldots \ldots \ldots \ldots \ldots$

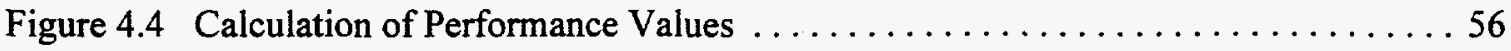

Figure 4.5 AFTM Vehicle and Fuel Choice Market Shares ................ 59

Figure 5.1 Vehicle Type Market Shares Sensitivity to Elasticity Assumptions . . . . . . 65

Figure 5.2 Fuel Type Market Shares Sensitivity to Elasticity Assumptions . . . . . . . . 67

Figure 5.3 Fuel Type Market Shares Reformulated Gasoline and Option Value . . . . . . 68

Figure 5.4 Vehicle Type Market Shares Sensitivity to Hedonic Values . . . . . . . . . . . 69

\section{LIST OF TABLES}

Table 2.1 Fuel and Vehicle Choices .......................... 18

Table 2.2 Relative Energy Content and Refueling Frequency of Gasoline and

Alcohol Fuels . . . . . . . . . . . . . . . . . . . . . . . . 19

Table 3.1 Estimation of Battery Electric Vehicle Characteristics $\ldots \ldots \ldots \ldots \ldots \ldots \ldots 28$

Table 3.2 Alternative Fuel Vehicle On-Board Fuel Storage Capacities and

Refueling Times . . . . . . . . . . . . . . . . 30

Table 3.3 Variation and Correlation Among Fuel Prices, $1978-1992 \ldots \ldots \ldots \ldots \ldots \ldots 35$

Table 3.4 Estimated Option Values for Pairs of Alternative Fuels and Gasoline

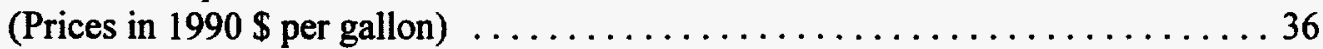

Table 3.5 Incremental Initial Cost Estimates for AFVs $\ldots \ldots \ldots \ldots \ldots \ldots \ldots \ldots \ldots \ldots$

Table 3.6 Power to Weight Changes for Alternative Fuel Vehicles . . . . . . . . . . . 39

Table 3.7 Loss of Cargo Capacity to Energy Storage in Gaseous-Fueled and

Battery Electric Vehicles . . . . . . . . . . . . . . . . . 41

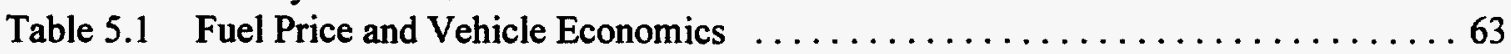

Table 5.2 Alternative Elasticity Assumptions for Vehicle and Fuel Choices . . . . . . . 64

Table 5.3 Alternate Values for Vehicle Attributes and Refueling Time $\ldots \ldots \ldots \ldots \ldots 6$ 


\section{ACKNOWLEDGMENTS}

The author wishes to thank those who helped him in the course of this work and made a significant contribution to the theory and execution of the AFVC model. Remaining flaws are, of course, the author's responsibility. Paul Leiby, developer of the AFTM model after Alan Manne has been an invaluable source of insights. Frank Southworth provided important guidance concerning the nested multinomial logit model and its proper interpretation. Carmen Difiglio, Ben Massell, Barry McNutt, and Lew Fulton provided vision and coordinated work on this project with the overall research effort of which it is a part. Harry Vidas deserves special thanks for his painstaking examination of the initial AFVC spreadsheet, numerous suggestions for its improvement and streamlining, as well as the implementation of the improved version described herein. Finally, thanks are due to Debbie Bain for her careful attention to the preparation of this report. This report is dedicated to the memory of Michael Greene. 
viii 


\begin{abstract}
This report describes the theory and implementation of a model of alternative fuel and vehicle choice (AFVC), designed for use with the U.S. Department of Energy's Alternative Fuels Trade Model (AFTM). The AFTM is a static equilibrium model of the world supply and demand for liquid fuels, encompassing resource production, conversion processes, transportation, and consumption. The AFTM also includes fuel-switching behavior by incorporating multinomial logit-type equations for choice of alternative fuel vehicles and alternative fuels. This allows the model to solve for market shares of vehicles and fuels, as well as for fuel prices and quantities. The AFVC model includes fuel-flexible, bi-fuel, and dedicated fuel vehicles. For multi-fuel vehicles, the choice of fuel is subsumed within the vehicle choice framework, resulting in a nested multinomial logit design. The nesting is shown to be required by the different price elasticities of fuel and vehicle choice. A unique feature of the AFVC is that its parameters are derived directly from the characteristics of alternative fuels and vehicle technologies, together with a few key assumptions about consumer behavior. This not only establishes a direct link between assumptions and model predictions, but facilitates sensitivity testing, as well. The implementation of the AFVC model as a spreadsheet is also described.
\end{abstract}




\section{ALTERNATIVE FUELS AND VEHICLES CHOICE MODEL}

\section{CONTEXT}

Development of the Alternative Fuels and Vehicles Choice Model (AFVC) is part of an ongoing study of the Costs and Benefits of Alternative Fuel Use in the U.S. Transportation Sector (U.S. DOE, 1988). Information and analytical tools developed in the course of that study are being applied to answer questions posed by Section 502(b) of the Energy Policy Act of 1992 (EPACT) concerning the technical and economic feasibility for alternative fuels to replace petroleum fuels, reduce greenhouse gas emissions, and displace U.S. energy imports. The act sets goals of $10 \%$ replacement by 2000 and $30 \%$ by 2010 . The key analytical tool for this assessment is the Alternative Fuels Trade Model (AFTM), a computer model of world supply and demand for liquid fuels (Manne, 1989; Leiby, 1993). The Alternative Fuels Trade Model (AFTM) represents world supply and demand for liquid fuels by means of an optimization model comprising 1) resource supply, 2) conversion into liquid fuel products, 3) transportation and distribution, and 4) demand for fuels (Leiby, 1993). A unique feature of the AFTM is the inclusion of the choices of alternative fuel vehicles and alternative fuels in solving for a world energy market equilibrium. It accomplishes this by incorporating a multinomial logit (MNL) model into the AFTM's objective function (Leiby and Greene, 1993). This memorandum sets forth the methodology of the AFVC model and explains how the parameters of the model are developed and converted into an appropriate format for use in the AFTM.

The philosophy underlying the AFVC model is to maintain a direct and explicit linkage between assumptions about fuels, vehicles, and consumer behavior, and the resulting model coefficients. The model's parameters do not emerge from a "black box," but are instead derived from assumptions about vehicles and consumer behavior that must be stated explicitly. In order to forecast the demand for new commodities such as alternative fuels and vehicles, a number of important assumptions must be made about, 1) what attributes influence the choices of fuels and vehicles, 2) how consumers will value the differences among fuels and vehicles, and 3 ) how sensitive choices will be to fuel prices. 
Fuel prices are the only variables in the AFTM affecting fuel and vehicle choices.' Calibration of the AFVC model begins by stipulating the characteristics of vehicles and fuels that are expected to be important in consumers' decision-making. Next, each important attribute of the vehicles and fuels is quantified. Typical (average) values (\$/unit) for each characteristic are then used to obtain a value in dollars for each attribute. These values can be directly translated into coefficients of the MNL choice model, once the price elasticities of fuel and vehicle choices are specified.

The steps required to calibrate the AFVC model are illustrated in Figure 1.1. Boxes indicate where critical assumptions are introduced. The calibration method relies on existing studies of consumer choices of conventional and alternative fuels, analyses of surveys of consumer preferences for alternative fuels, existing technology assessments for alternative fuel vehicles, and assumptions about key factors such as the discount rate and value of time. By deriving parameters from specific assumptions about consumer behavior and vehicle attributes, the method requires a clear statement of the suppositions on which the model's predictions are based. Uncertainty about many important aspects of the future markets for alternative fuels and vehicles makes it important both to be clear about what assumptions have been made, and to be able to change assumptions and repeat the analysis. The AFVC methodology maintains a clear record of assumptions so that their effects on predicted outcomes can be understood.

Modeling demand for novel products for which there is no history of market experience is always tricky. Existing studies of consumer demand for alternative fuels offer a reasonable consensus about which fuel characteristics are important, but permit only a limited quantification of consumers' willingness to pay for fuel attributes. In addition, some key characteristics of future alternative fuel vehicles are only approximately known at this time. For some alternative fuels, positive and negative characteristics of the fuel may offset each other to a substantial degree, leaving market share to be determined by price and intangible or unpredictable factors such as consumer perceptions of fuel "quality," or individual willingness to pay for fuels with social rather than private benefits. The price responsiveness of fuel and vehicle demand in the context of a well-developed alternative fuels market is also not definitively known. Existing econometric studies of conventional fuel type choice, indicate very high price elasticities $(-10$ to -40$)$ of demand in a variety of contexts. The price elasticity of vehicle type choice is also likely to be quite high for most vehicle types. To the extent that alternative fuels are perceived to be nearly equivalent to gasoline, vehicle and fuel choice is likely to be highly sensitive to very small price or quality differences.

\footnotetext{
${ }^{1}$ Because the value of at least one attribute is a function of fuel prices, the method does not allow a fully simultaneous determination of fuel prices and fuel and vehicle choices. This shortcoming can be overcome by iteratively solving the AFTM and recomputing parameter values.
} 


\section{FIGURE 1.1 ALTERNATIVE FUELS AND VEHICLES CHOICE MODEL FLOWCHART OF CALIBRATION PROCESS}

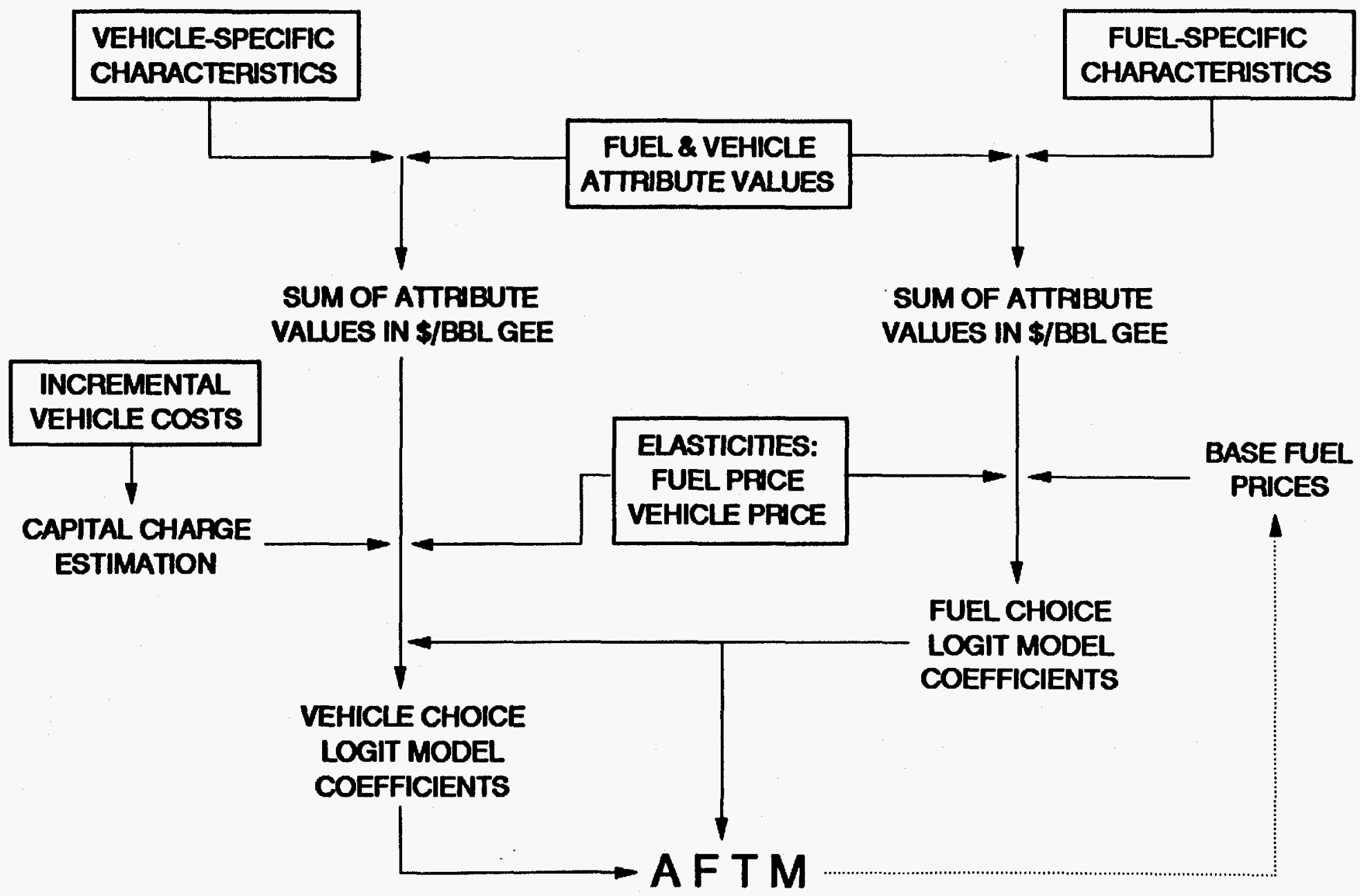


What is required is a modeling method that recognizes the existence of uncertainties, permits what is known to be used in a rigorous manner, and requires all critical assumptions to be made explicitly. The AFVC model accomplishes these goals by starting with a theoretically rigorous model structure, and calculating all of its parameters from data or explicitly stated assumptions. The AFTM incorporates the AFVC model into its objective function in order to predict the market shares that maximize social welfare (Leiby and Greene, 1993).

The process of calibration begins with the specification of key assumptions about consumer behavior and fuel and vehicle attributes (Figure 1.1). These are entered in a spreadsheet which uses them to calculate fuel attribute values in 1990 dollars per barrel of gasoline equivalent. Dollar values of fuel attributes are first used to estimate coefficients for the fuel choice decisions for multi-fuel vehicles, which are then subsumed, or nested, in the vehicle choice model.

Based on assumptions about vehicle use, depreciation rates, fuel economy, length of ownership, and discount rates, also entered in the spreadsheet, price differences among vehicles are converted to price differences per barrel of gasoline equivalent. Price slope coefficients are then calculated from three items of data supplied by the user: 1) a price elasticity at 2) a given market share and 3) initial vehicle price ${ }^{2}$. The price slope is then used to transform the dollar values of attributes into alternative-specific constants for the logit model. As a result, the coefficients of the MNL choice model in the AFTM depend directly and entirely on the assumptions made about vehicle characteristics and related factors.

Because the AFTM is a static equilibrium model, solutions represent long-run adjustments of supply and demand to prices. The AFTM does not attempt to represent the dynamic process of new vehicle purchases and the aging and retirement of vehicle stock. Similarly, the expansion of alternative fuel vehicle manufacturing capability and alternative fuel processing and distribution networks are not represented. The stock of AFVs, and the choice of fuel by Flexible Fuel Vehicles (FFVs) and Dualor Bi-Fuel Vehicles (DFVs) are determined at the same time and are, by assumption, in long-run accord with fuel prices. It is therefore desirable that the choice of vehicle reflect the consumer's evaluation of the fuels the AFVs can use and that this evaluation be consistent with the modeling of fuel choices. This is accomplished by an explicit linking of the fuel and vehicle choice logit models. Fuel attribute values from the fuel choice logit model enter into the vehicle choice model in a way that reflects their expected value to the vehicle purchaser. This linkage between the fuel

${ }^{2}$ Price slope here refers to the coefficient of price in the consumer's indirect utility function as distinguished from the derivative of market share with respect to fuel price. 
and vehicle type choice models insures consistent parameter values for the two models. It does not, of course, remove the inherent limitations of static equilibrium models. The AFTM assumes that there has been sufficient time for products to be developed, sold, and penetrate the fleet, manufacturing and fuel supply capacity to be expanded, and that prices have been stable for long enough to allow the market to reach a stable equilibrium. Clearly, world energy markets are anything but static and so model solutions are probably best interpreted as directions in which markets are likely to move, and even then must be interpreted cautiously.

Assuming a Jong-run market equilibrium has one enormously important implication for the AFVC model. The model treats all alternative fuels and vehicle technologies equally. More specifically, it assumes that every AF is widely available (like gasoline) and that every AFV technology is available for every make and model of vehicle consumers may desire. This assumption is unrealistic for dynamically evolving real world markets. Even in a long-run equilibrium market, it is likely that economies of scale would limit the availability of the less popular AFV technologies and AFs. Thus, the AFVC methodology may also overstate the market shares of less popular fuel and vehicle types. Modeling the crucially important dynamics of alternative fuels markets is a subject for future research. 


\section{SPECIFICATION OF A VEHICLE AND FUEL CHOICE MODEL}

Alternative fuels and alternative fuel vehicles are unfamiliar commodities to the vast majority of consumers. Despite three decades of efforts, predicting demand for novel commodities remains on the frontier of economic analysis. Predicting the demand for alternatives to conventional vehicles is inherently tricky because direct historical experience from which to draw inferences about future behavior is lacking. Researchers have developed two approaches for coping with inadequate historical data on consumer demand for new commodities, such as alternative fuels and vehicles. One approach is to develop synthetic data, by means of surveys which pose hypothetical questions about purchases of vehicles and fuels to potential consumers (e.g., Golob, et al. 1992). Such surveys produce information about consumers' "stated preferences" which may or may not match the "revealed preferences" they express by their actual purchase decisions. The alternative is to draw inferences, based on revealed preferences expressed in analogous but different situations, about how consumers value the attributes of similar goods. Analogous situations might include, for example, choices among different grades, brands, and service levels for gasoline, choice of gasoline or diesel engines for automobiles and light trucks, and choices among different types of automobiles. Both methods have important shortcomings and, indeed, there is no generally accepted method for predicting the demand for new commodities. ${ }^{3}$ While each has advantages and disadvantages, the latter approach was chosen here for the reasons given below.

A real danger in stated preference surveys is that respondents will provide biased answers not representative of their actual behavior. Respondents have a tendency to tell an interviewer what they think he wants to hear, or what they believe is the socially correct response. Alternative fuel vehicles are often perceived to be environmentally "clean" vehicles that would help relieve the country of its dependence on imported petroleum. Both of these are public rather than private benefits, creating exactly the kinds of conditions that tend to produce biased responses in stated preference surveys. Furthermore, when a survey deals with novel commodities respondents often have great difficulty evaluating technologies with which they have no first-hand experience. They

\footnotetext{
${ }^{3}$ The numbers of relevant attributes, correlations among them, as well as difficulties in defining and measuring attributes often make it difficult to infer reliable attribute values from past choices. Inferences from surveys based on hypothetical choices are usually ambiguous due to likely differences between what respondents say they will do (stated preferences) as opposed to what they actually will do (revealed preferences).
} 
may not fully appreciate the implications of certain vehicle or fuel characteristics, and they may also introduce assumptions and biases not presented to them in the survey. Once choice models have been estimated using the survey data, there is no way to sort out these potential biases.

Analogizing from actual behavior in similar situations also has deficiencies. Situations are never exactly analogous and it is not possible to control for all the dissimilar factors. In addition, existing studies do not cover all of the differences between alternative and conventional fuel vehicles. A good example of this might be the recharging of battery-powered electric vehicles. The gaps must be filled in by assumption. Rather than being a disadvantage, we view this as an advantage, since the assumptions on which the analysis is based are explicit, rather than hidden. It is a useful property for the purposes of policy analysis to have conclusions that can be directly related to assumptions. It also facilitates testing the sensitivity of results to the assumptions that have been made.

\subsection{HEDONIC DEMAND AND RANDOM UTILITY}

Predicting demand for new commodities is one of the most difficult problems in economics. Without the benefit of historical data from which to infer patterns of consumer behavior, it is difficult to formulate a credible quantitative model of demand. The theory of hedonic demand was developed to address this situation indirectly, by postulating that consumers' utility depends on the attributes of goods rather than the good, per se (e.g., Lancaster, 1966). Thus, if the value of attributes could be determined, demand for novel goods might be inferred from the values of their attributes. When predicting consumers' choice among a set of discrete options, the hedonic demand premise led to the development of random utility theory. Random utility theory extends the hedonic demand concept by postulating that in addition to the value attached to observed attributes, there is a portion of the utility of a good that can be considered random (McFadden, 1974). Let $U_{\text {in }}$ stand for a quantitative measure of the utility, or satisfaction, consumer $n$ derives from good $i$, and $V\left(x_{i k}\right)$ represent the function that assigns a quantitative value to the observable attributes $\left(x_{k}\right)$ of good $i$, and let $\epsilon_{\mathrm{in}}$ be the random component for good $\mathrm{i}$ and consumer $\mathrm{n}$.

$$
U_{i n}=V\left(\boldsymbol{x}_{i n}\right)+\epsilon_{i n}
$$


An important implication of equation (2.1) is that no alternative has a strictly higher utility than any other. Rather it has a greater expected utility, $\mathrm{V}\left(\mathbf{x}_{\mathrm{ik}}\right)$, or a greater probability of having a higher utility.

The random utility component represents a multitude of factors left out of the measured utility function V. Econometricians have explained its role as follows:

"We start with the assumption that consumers are rational in the sense that they make choices that maximize their perceived utility subject to constraints on expenditures. However, there are many errors in this maximization, because of imperfect perception and optimization, as well as the inability of the analyst to measure exactly all of the relevant variables." (Maddala, 1992, p. 59)

Maddala has further described the random component as a factor,

"...that captures unobserved variations in tastes and in the attributes of alternatives and errors in the perception and optimization by the consumer." (Maddala, 1992, p. 60)

If consumers make errors in perception and optimization, it implies that even they may not know at the time they make their choices how satisfied they will be with them. Thus, the buyer of a new car is not entirely certain at the time of purchase how satisfied he will be with it: a very plausible assumption.

In the multinomial logit model, there is a direct relationship between the sensitivity of choices to price and the relative importance of the random component in the choice decision. The proof of this can be found in Appendix A. It also squares with intuition. The more certain we are of the value of our options, the more the decision will turn on price. Put another way, the more similar the choices are, given the factors accounted for in the function $\mathrm{V}$, the more price sensitive the choice will be. In economic terms, this is another way of saying the choices are close substitutes (conditional on $\mathrm{V}$ ). The practical result of this special relationship for the MNL model is that when price elasticities are specified so also are the random error components.

The essence of the AFVC approach is the following. First, we specify an explicit and rigorous model of the alternative fuel vehicle choice process. Next we enumerate the factors to be considered in the choice process. Fuels and vehicles are then described by specific values for each factor. Drawing on the existing literature on vehicle and fuel choice and travel behavior, values are developed for each relevant factor, including prices. Parameters of the vehicle choice model are 
then computed directly from these data and assumptions. The result is a choice model whose parameters can be directly traced to vehicle and fuel characteristics, and assumptions about consumers' valuation of them.

\subsection{THEORY AND MATHEMATICAL FORM OF THE AFVC MODEL}

It seems natural to consider the alternative fuel choice decision as composed of two, sequential steps: 1) choice of vehicle, and 2) choice of fuel for that vehicle. In real life, this is the temporal order in which the decisions would be made. In the context of a long-run static equilibrium model such as the AFTM model, however, the choices are made simultaneously. In other words, market shares are determined simultaneously for the elementary choices consisting of a vehicle and fuel combination (e.g., "FFV using Gasoline," "NGBiF using CNG," etc.; see Figure 2.1). The temporal sequencing is not relevant. However, for reasons other than the timing of decision-making, it will prove useful and appropriate to structure the fuels and vehicles choice model in a way that distinguishes between vehicle and fuel choices.

It also seems obvious that the fuels a vehicle can use and their characteristics should influence the choice among vehicle types. The model structure proposed here explicitly embeds, or nests, the fuel choice decision for a multi-fuel vehicle within the vehicle choice decision. Factors affecting fuel choice thus directly influence vehicle choice, and the parameters of the vehicle choice model are composed in part of the parameters of the fuel choice model. In this section, the structure of the choice model is described, the multinomial logit model and the concept of generalized cost used here to compute coefficients for the model are then introduced, and it is shown how the choice structure gives rise to a generalization of the MNL model termed the nested MNL (NMNL) model.

There is an extensive literature on the subject of models of "qualitative responses" (McFadden, 1974; Amemiya, 1985; Maddala, 1992) in which individuals choose one option from a set of discrete alternatives. These models have been widely used in transportation to represent choices among destinations for trips and modes of transport (e.g., Ben-Akiva and Lerman, 1987) and to represent consumers' decision-making in choosing an automobile (e.g., Train, 1986). The most widely used type of qualitative choice model is the multinomial logit model (MNL) which combines relative mathematical simplicity, enormous flexibility, and ease of estimation with a rigorous derivation based on economic theory. Most often, the MNL model is used to represent the choices of individual (or disaggregate) decision-making units such as households or persons. Its use in 


\section{FIGURE 2.1 NESTED STRUCTURE OF ALTERNATIVE FUEL AND VEHICLE CHOICE DECISIONS}

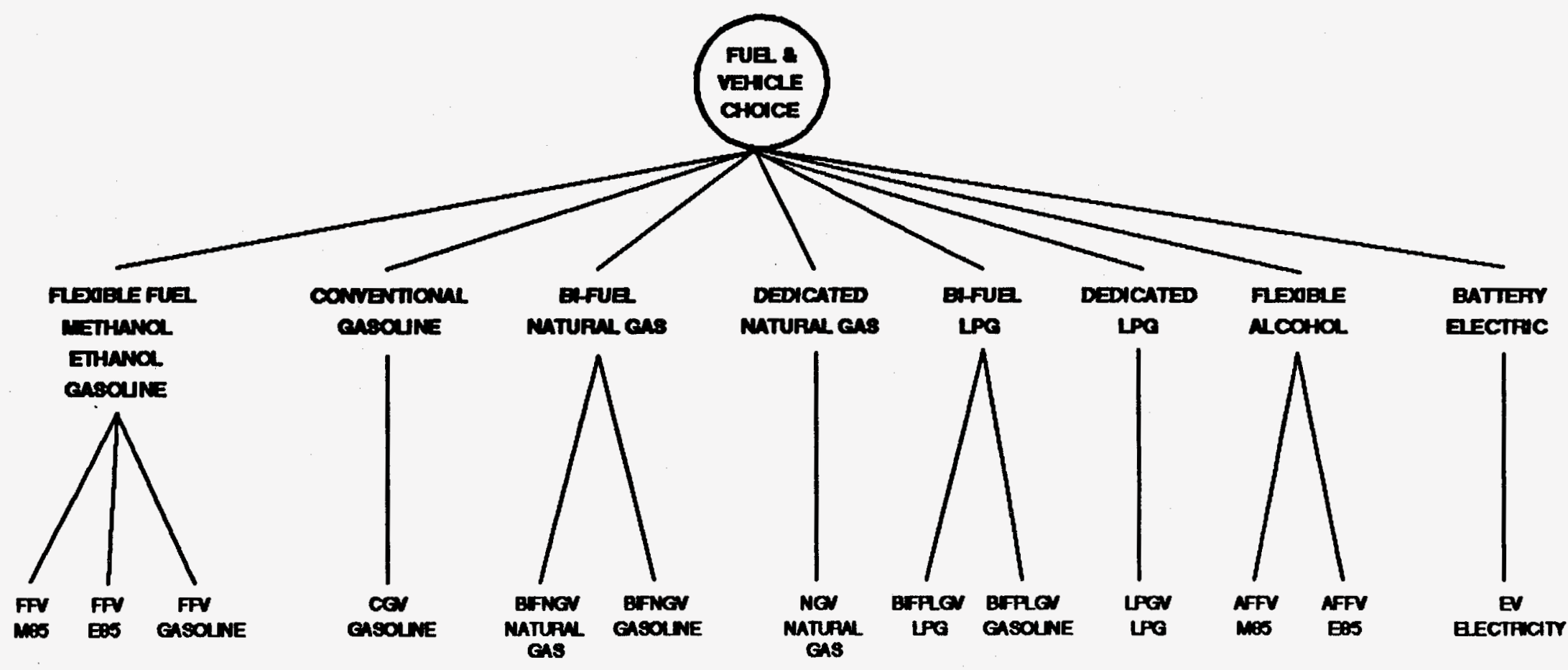

\section{ELEMENTARY CHOICES}


representing macroeconomic behavior has traditionally been thought to give rise to problems of aggregation bias unless appropriate simulation methods are used (e.g., Train, 1986, Ch. 6). However, the model can also be interpreted as representing the average behavior of a group of consumers. Recently, Anderson, De Palma, and Thisse (1988) have shown how a macroeconomic version of the MNL model can be derived based on a "representative consumer" or a population with diverse tastes.

The multinomial logit model is construed in this report to be a representation of the general or typical behavior of a population, allowing a random error term to represent general deficiencies in

$$
U_{i}=V\left(X_{i}\right)+\varepsilon_{i}
$$

the model, including variations across individuals. We assume that the goodness or utility of an alternative can be represented by a function,

in which the $X_{i}^{\prime}$ s are observable variables describing option $i, V$ is a linear utility function, and the $\varepsilon_{\mathrm{i}}$ represents, in Madalla's (1992, p. 60) words,

"...a residual that captures unobserved variations in tastes and in the attributes of alternatives and errors in the perception and optimization by the consumer."

If the error terms are independently and identically distributed and follow a type I extreme value distribution with probability density

$$
f\left(\varepsilon_{i}\right)=\beta \exp \left(-\beta \varepsilon_{i}-\exp \left(-\beta \varepsilon_{i}\right)\right)
$$

then it can be shown (e.g., see Maddala, 1992, pp. 60-61) that the probability of option i being chosen by any given consumer is given by the multinomial logit function of its utility, $V\left(X_{i}\right)=$ $\beta C\left(X_{i}\right){ }^{4}$

${ }^{4}$ The proof is given in Appendix A. Throughout this exposition, we use probability and market share interchangeably, represented by the letter $\mathrm{s}$. 


$$
s_{i}=\frac{e^{\beta C_{i}}}{\sum_{j=1}^{n} e^{\beta C_{j}}}
$$

We have chosen to represent utility as a constant, $\beta$, times a "generalized cost" function $C_{i}=C\left(X_{i}\right)$, in order to show the relationship between the price sensitivity of choice probabilities, or market shares, and the parameter of the extreme value distribution function. The linear utility function can be written as a sum of other variables times their coefficients $\left(a_{k}{ }^{\prime} s\right)$ plus $\beta c_{i}$, where $c_{i}$ is the cost or price of the $i^{\text {th }}$ option.

$$
V_{i}=\beta c_{i}+\sum_{k=1}^{K} a_{i k} X_{i k}=\beta\left(c_{i}+\sum_{k=1}^{K} \frac{a_{i k}}{\beta} X_{i k}\right)=\beta C_{i}
$$

Thus, $\beta$ is both the price slope of the utility function and the scale parameter of the random error term. This has the following useful interpretation. The more price sensitive the choice among options is, the smaller the variance of the random utility component, i.e. the more completely the observed variables reflect the important factors in consumers' decision-making. This is an intuitively satisfying property. If, excepting the observed variables, the choices are extremely similar, they should be very close substitutes and therefore choices among them should be very price elastic. This property will be helpful when it comes time to specify parameters for the MNL model, and we will also use it to explain why a nested logit structure may be the most appropriate structure to represent vehicle and fuel choice.

The price elasticity of choice in the MNL model depends on $\beta, c_{i}$, and $s_{i}$, the market share.

$$
\eta_{i, c_{i}}=\frac{\partial s_{i}}{\partial c_{i}} \cdot \frac{c_{i}}{s_{i}}=\beta c_{i}\left(1-s_{i}\right) \quad-\beta=\frac{\eta_{i, c_{i}}}{c_{i}\left(1-s_{i}\right)}
$$

Equation (2.6) implies that elasticities will be very high at low market shares and decrease as shares approach market dominance. Equation (2.6) also provides a means of estimating the cost parameter $\beta$ if the elasticity at a particular market share and price is known.

It seems reasonable to assert that the choice among fuels for a given type of alternative fuel vehicle will be more price sensitive than the choice of vehicle type. Interpreting this in terms of the 
parameter $\beta$, one would say that the variation in unobserved attributes is less for choice of fuel than for choice of vehicle. This seems a very plausible assertion since the fuels are to be used in the same vehicle, making all vehicle-specific attributes constant. There is ample evidence, for instance, that price elasticities of choice of car type are in the range of -1 to -5 , while the elasticities of choice of type of gasoline have been estimated to be -20 or higher at typical market shares. Whenever $\beta$ parameters differ for definable subsets of the full choice set, a special type of multinomial logit model, called the nested multinomial logit model (NMNL) provides a more accurate representation of the decision process. Suppose we divide the elementary choice set (all vehicle fuel combinations) into subsets, such that a subset contains the elementary choices corresponding to a particular type of alternative fuel vehicle. For example, flexible fuel vehicle (FFV) using gasoline, FFV using M85, and FFV using E85 would be in one subset ${ }^{5}$, while bi-fuel natural gas vehicle (BiNGV) using compressed natural gas and $\mathrm{BiNGV}$ using gasoline would be in another. This choice structure is illustrated in Figure 1.1. The probability of choice of fuel type $j$ used in vehicle type $i, s_{i j}$, can always be expressed as the product of the (conditional) probability of choice of fuel type $\mathrm{j}$ given vehicle type $i$ has been chosen, times the (marginal) probability of choice of vehicle type $i$.

$$
s_{i j}=s_{j \mid i} \cdot s_{i}
$$

We assume the choice of fuel within a subset is multinomial logit, with generalized cost $c_{i j}$ and price slope $\mu_{\mathrm{i}}$ (price sensitivity is constant within a subset but may vary across subsets). The conditional probability of choice of fuel type $j$, given vehicle type $i$, is then,

$$
s_{j \mid i}=\frac{e^{\mu_{i} c_{i}}}{\sum_{k=1}^{n_{i}} e^{\mu_{i} c_{i t}}}
$$

The probability of choice of vehicle type $i$ depends on its generalized cost, $c_{i}$ and the cost slope for vehicle type choice, which we will represent by $\beta$. Recall that $\beta$ is also the scale parameter of the distribution of random influences (unobserved factors, differences in tastes, imperfect information, etc.) for the vehicle type choice decision. The generalized cost for vehicle type $i$ is composed of factors that do not vary over fuel types, and of the average generalized cost of the fuels that vehicle type i can use. If it were not for the random error term, the average generalized cost would be the

\footnotetext{
${ }^{5} \mathrm{M} 85$ is a blend of $15 \%$ gasoline and $85 \%$ methanol. E85 is similarly a $15 \% / 85 \%$ blend of gasoline and ethanol.
} 
weighted average of the generalized costs, $c_{i j}$, of the fuel options in subset $i$, the weights being the fuels' market shares. But if it were not for the random error term, only the fuel with the lowest generalized cost would be chosen by utility maximizing consumers, and so the average generalized cost would be that of the lowest cost fuel. Since we assume there are random components to the generalized cost, the average cost is given by (Williams, 1977),

$$
\bar{c}_{i}=\frac{1}{\mu_{i}} \ln \sum_{j=1}^{n_{i}} e^{\mu_{f_{i j}}}+k
$$

where the $\mathrm{k}$ can be omitted since it has no effect on the choice probabilities (Fisk and Boyce, 1984). The generalized cost of vehicle type $i$ is the sum of the vehicle specific costs (which we will designate $u_{i}$ ) and the average cost of the choice of fuel type. ${ }^{6}$ The probability of choice of vehicle type $\mathrm{i}$ is then,

$$
s_{i}=\frac{e^{\beta\left(u_{i}+\bar{c}_{j}\right)}}{\sum_{k=1}^{M} e^{\beta\left(u_{k}+\bar{c}_{k}\right)}}
$$

where $M$ is the number of vehicle types. The coefficient of the logsum term is the ratio $\beta / \mu_{i}$, the price coefficient of the vehicle choice decision divided by the price coefficient of the fuel choice decision (the prices must be in the same units). This ratio will always lie between zero and one if the nesting has been properly structured. If the ratio equals one, then there is no nesting structure, as shown below. This property of the NMNL logit model has an interesting economic interpretation, namely that choices within a nested subset must be closer substitutes (their market shares must be more sensitive to price) than choices at the higher level. Put another way, the random factor in the choice decision must be smaller within a nest than at a higher level in the choice structure. In the alternative fuels and vehicles choice model, this implies that for the vehicle choice decision, the unobserved error component must be larger (the price elasticity must be smaller) than for the fuel choice decision.

The product of equations (2.8) and (2.10) comprises a nested multinomial logit model for the joint probability of vehicle and fuel type choice $\left(s_{i j}\right)$. If we assume that $\mu_{i}=\beta$ for all $i$, then the nested

${ }^{6}$ It is imperative that these costs be expressed in the same units. If vehicle costs are in terms of initial capital costs, fuel costs must be expressed in terms of costs capitalized over the vehicle's lifetime to present value. Likewise, if fuel costs are to be expressed in dollars per unit (e.g., per barrel) then vehicle costs must be expressed in dollars per unit of fuel consumption. 
model collapses to a simple multinomial logit model. By substituting equation (2.9) in equation $(2,10)$, substituting $\beta$ for $\mu_{i}$, and multiplying equations (2.8) and (2.10) together (since $s_{i j}=s_{j i j} \cdot s_{i}$ ), and simplifying one obtains the following,

$$
s_{i j}=\frac{e^{\beta\left(y_{i}+c_{i j}\right)}}{\sum_{k=1}^{N} e^{\beta\left(u_{k}+c_{i j}\right)}}
$$

Equation (2.11) is a simple multinomial logit model. The fact that generalized cost has been separated into vehicle-specific and fuel-specific components is a result of the choice of notation. Thus, it is the differences in price sensitivity $\left(\beta \neq \mu_{i}\right)$, or equivalently the differences in the relative importance of the error component, that creates the nested structure. Since research on vehicle and fuel choice, as well as intuition, strongly suggest that the elasticity of fuel choice for a multi-fuel vehicle will be more price sensitive than the choice of vehicle, the NMNL structure is preferred over the simple multinomial logit model.

\subsection{FACTORS IN THE FUEL CHOICE DECISION}

The first step in constructing the AFVC model is to identify the characteristics consumers will consider in choosing vehicles and fuels. In this section we describe factors that are believed likely to influence consumers' choice of alternative fuels and vehicles. The discussion draws heavily from the extant literature. In Chapter 3, we explain how factors are quantified and translated in NMNL model parameters.

Some factors that are important today should not be included in AFVC model because they pertain to the transition to alternative fuels and would disappear in a mature market. As long as there are few AFVs on the road, the low level of AF demand will not support an extensive network of refueling stations. The difficulty in finding an alternative fuel or the extra distance that must be traveled to obtain it will discourage demand for alternative fuels. In the early stages of fuel and vehicle introduction, there may also be unforeseen reliability or performance problems that can have a drastic effect on consumers' acceptance of alternative fuel vehicles and alternative fuels. Experience in the U.S. with diesel automobiles illustrates the importance of "start-up" problems with vehicle technology (Kurani and Sperling, 1988). But the U.S. diesel car experience also illustrates that such problems can be overcome, and shows the ultimate importance of a fuel cost advantage to the market success of alternative fuels (Greene, 1986). Because the AFTM is a long-run static 
equilibrium model, we assume that all of these "start up" problems have been solved. We also assume that fuel is readily available to those who wish to buy it. Ignoring fuel availability costs, however, will cause us to overstate the market shares of fuels with a small share of the market.

Surveys of motorists have determined that at least the factors listed in Table 2.1 are important to the decision to choose an alternative fuel (e.g., Golob, et al., 1992). Some characteristics are associated with vehicle technologies and do not depend on which fuel is being used. Others are fuel-specific and occur only when the fuel is used. Thus, a multi-fuel vehicle will have different characteristics depending on which fuel is being used.

The factors included in the AFTM AFV Choice Model are highlighted in boldface (Table 2.1). The remaining factors and the manner in which they are treated in the AFV Choice Model are discussed below.

Fuel Availability is consistently rated a major concern by prospective alternative fuel buyers Golob, et al., 1992; Kurani, 1992). In practice, however, fuel availability rarely turns out to be a problem for those actually using alternative fuel vehicles, even if only $10 \%-20 \%$ of the stations offer the fuel (Sperling and Kurani, 1987; Kurani, 1993; Greene, 1989). Since it is likely that perhaps $10 \%$ of the stations would offer an alternative fuel which comprised only $1-2 \%$ of total gallonage, is likely to be a problem during only the early stages of fuel introduction, or only if fuel sales are very small. In either case, when using a long-run equilibrium model it seems reasonable to assume that fuel availability is not a problem, but use caution in interpreting the model's predictions. ${ }^{7}$ For a fuel with a large equilibrium market share (say $>10 \%$ ), fuel availability is a transitory problem, and therefore not appropriate for a market equilibrium model. For fuels with a very small market share (say $<2 \%$ ), fuel availability is likely to be a sufficiently serious problem to relegate the fuel to niche markets. Thus, fuel availability is likely to be a crucial factor only for fuels with predicted shares in single digits.

Refueling difficulty may be of two kinds: 1) increased time required for refueling, and 2) increased difficulty or complexity of the refueling task. Since alcohol fuels are liquids and will be handled

\footnotetext{
${ }^{7}$ An alternative option would be to incorporate a simultaneous relationship into the AFTM so that the cost of fuel availability would be high if fuel sales were very small but decreased rapidly at markets shares over $2 \%$, or so. Our approach is to assume that fuel availability is not a problem, but to be aware that if the AFTM model predicts market shares of less than $2 \%$ for alternative fuels, the true market share is probably much lower.
} 
Table 2.1 Fuel and Vehicle Choices

Fuel Characteristics

1. Cost

2. Fuel Availability

3. Refueling Difficulty

Range (Frequency)

Refueling time and convenience

4. Fuel Quality

Performance (acceleration or power)

Effect on Vehicle Reliability and Maintenance

Health and Safety

Aesthetics

5. Social Benefits

Emissions

Oil Dependence

\section{Vehicle Characteristics}

1. Cost

2. Reliability and Maintenance

3. Performance (acceleration or power)

4. Health and Safety

5. Capacity (to carry people and cargo)

6. Value of Multi-Fuel Option

7. Combined Effects of Fuel Characteristics

exactly like gasoline, complexity of the refueling task will be the same for ethanol and methanol as for conventional gasoline. LPG is also handled as a liquid under modest pressure and as such has about $2 / 3$ the energy density as gasoline, so that refueling should be only slightly more complex than for gasoline or alcohol. CNG refueling, however, must be done at pressures of approximately 3,000 psi. Even "fast-fill" CNG refueling is likely to take a few minutes longer than refueling with liquid fuels. Battery electrics are a special case. Although "fast recharge" technologies exist and may be improved in the future, we assume that slow charge over a period of six hours will be the norm. But battery recharging will not fully occupy the motorist's time the way refueling does. Thus, although 
the time required is much longer, it should not be valued at the same rate since it does not require the motorist's full attention.

Range, or refueling frequency, is a function of the energy density of the alternative fuel relative to gasoline, the capacity of the storage device, and the relative efficiency of the vehicle when using the alternative fuel. Alternative fuels vary considerably in their energy densities per unit volume (Table 2.2). Though available evidence is not conclusive, it appears that fuel-flexible and bi-fuel vehicles achieve roughly equal fuel economy on a gallon of gasoline equivalent energy basis (McNutt, 1993). Alcohol flexible vehicles not designed to use gasoline may achieve up to $10 \%$ better MPG (Interagency Commission on Alternative Motor Fuels, 1991, p. 22). The far greater energy efficiency of electric drives, helps to mitigate the very low energy density of even advanced batteries.

Table 2.2 Relative Energy Content and Refueling Frequency of Gasoline and Alcohol Fuels

\begin{tabular}{lc}
\hline \multicolumn{1}{c}{ Fuel } & $\begin{array}{c}\text { Energy Content } \\
\text { (Btu/gallon) }\end{array}$ \\
\hline Unleaded Gasoline & 115400 \\
Methanol & 56560 \\
Ethanol & 75670 \\
M85 & 65386 \\
E85 & 81630 \\
CNG (3,000 psi) & 24700 \\
LPG & 83570 \\
Battery Electric & $2000 \dagger$ \\
\hline
\end{tabular}

$\dagger$ Assumes a sodium/sulfur battery with a volumetric energy density of $0.15 \mathrm{kWh} / \mathrm{liter}$.

Given a fuel tank of equal size, the lower energy densities of M85 and E85, for example, imply that FFVs when using them will require refueling about $75 \%$ or $40 \%$ more often, respectively. This is disadvantageous because it demands more of the consumer's time. If we assume a total of 6 minutes time used for each refueling, value time at $\$ 10$ per hour ${ }^{8}$, and assume that an average of $2 / 3$ of a tank is purchased per refueling, we arrive at an average refueling cost of $\$ 0.10$ per gallon of gasoline. ${ }^{9}$

\footnotetext{
${ }^{8}$ Ten dollars per hour (1990\$) is a reasonable estimate of the average value travelers attach to their time (Chui and MacFarland, 1986). We are not aware of specific estimates of the value of time spent refueling conventional vehicles.

9The assumption of 6 minutes is intended to represent the in-station refueling time, not including travel time to and from the station.
} 
By this same reasoning, the extra refueling required for M85 and E85 add an additional $\$ 0.07$ and $\$ 0.04$ to the cost per gasoline equivalent gallon of these fuels. These assumptions appear reasonable to us, and are comparable to (though slightly lower than) what can be inferred from the responses to a recent survey about alternative fuel vehicles conducted for the California Energy Commission (Golob et al., 1992). Battery electric vehicles are so different from liquid or gaseous fueled vehicles that it is difficult to compare them on a consistent basis. Even an EV with an advanced battery (a battery not available today) would require almost 60 gallons of volume to store the equivalent of one gallon of gasoline. Despite the fact that an EV is likely to be more than twice as efficient as a conventional vehicle, 60 gallons of batteries would permit an effective range of less than 100 miles for an advanced EV. Moreover, refueling would require approximately 6 hours. Clearly the refueling time of an EV cannot be valued at the same rate as that of a liquid or gaseous fueled vehicle, yet it still has value and vehicle owners would undoubtedly be willing to pay something to reduce it.

Fuel Quality issues could be significant, yet there is little basis at this time for assigning fuel quality values to different fuels. Four varieties of potential fuel quality issues have been raised, but due to inadequate information on consumer's perceptions of the qualities of alternative fuels we do not attempt to estimate values for them.

\section{Reliability of operation}

2. Maintenance costs

3. Health and safety (e.g., toxicity, flammability)

4. Aesthetics (smell, appearance)

For most fuel quality issues, there is insufficient evidence on which to base even a crude estimate of consumer perception. We do know that consumers will pay for premium and mid-grade gasoline, many of them despite the fact that their engines do not require the higher octane of premium. Higher octane, "premium grade" gasolines may in some cases contain more additives (e.g., to clean fuel injectors) than regular grade fuel, although there is considerable controversy over whether motorists are paying for perceived rather than real differences in fuel quality (Dougher, Hofmann, and Hogarty, 1990). Based on an econometric analysis of consumers' choices between leaded regular, leaded premium, unleaded regular, and unleaded premium, Greene (1989) estimated the average willingness to pay for higher octane fuel at 1-2 cents per octane number per gallon. This would imply a 5-10 cent per gallon willingness to pay for premium versus regular grade gasoline. To the extent that consumers are buying other premium qualities besides octane, these are included in the 1-2 cents/octane number/gallon estimate. Although there is some evidence that consumers will pay 
more for fuels they believe to have higher quality, there is presently very little basis for evaluating the value to consumers of the perceived quality of each alternative fuel.

We assume that all alternative fuel vehicles will be equally reliable and equally safe. Although there may well be some differences, it does not appear that reliability, maintenance, or safety and health effects will pose any particular problems for the alternative fuels we consider. It is likely that consumers will perceive different aesthetic values for alcohols, gaseous fuels, and electricity, but we know of no studies that can provide a basis for estimating monetary values for such aesthetic characteristics. It has been claimed that maintenance may be lower for EVs (DeLuchi, Wang, and Sperling, 1989), but battery replacement costs will probably eliminate this potential advantage, depending on the state of battery technology.

Vehicle performance characteristics that are related to fuel and engine type consist of driveability and acceleration capability (Bechtold, 1993). Driveability refers to ease of starting and a relatively smooth and linear response to the accelerator pedal. AFV fuel systems are already rapidly approaching the smooth and predictable response of conventional gasoline systems, and we see no reason to believe that AFV driveability will not be equal to gasoline vehicles in the 2000 to 2010 period.

Acceleration capability will vary, due to changes in 1) fuel properties (e.g., octane number), and 2) vehicle weight. The net effect of either type of change can be expressed as an effective change in the ratio of horsepower to weight. Octane ratings of 99 or 100 , together with a higher latent heat of vaporization should give flexible fuel vehicles higher power when running on alcohols. ${ }^{10}$ Dynamometer tests have shown a $6 \%$ gain in horsepower for engines optimized for gasoline, but running on M85 or E85 (Bechtold, 1993). Gaseous bi-fuel vehicles will have reduced acceleration. Bi-fuel natural gas vehicles (NGV) and LP gas vehicles (LPGV) deliver fuel to the engine in a gaseous rather than a liquid state. The fuel thus displaces air that would otherwise have been drawn into the cylinder, effectively decreasing the engine's displacement. This volumetric efficiency loss is estimated to be $10 \%$ for bi-fuel NGVs and $5 \%$ for bi-fuel LPGVs (Bechtold, 1993). Battery electric and bi-fuel gaseous energy systems add significantly to the weight of the vehicle. Bechtold (1993) has estimated weight increases of 3-4\% for LPG cars and light trucks, and 4-6\% for NGVs. The extra weight of batteries are likely to cause EVs to weigh 25-30 percent more than a comparable conventional vehicle. On the other hand, the electric motor can easily be sized to provide equal if

\footnotetext{
${ }^{10} \mathrm{Higher}$ latent heat of vaporization results in a greater absorption of heat from the air in the intake charge when fuel is injected into a cylinder. This produces greater cooling of the gases in the cylinder, reducing the work required to compress the charge, thereby increasing the engine's output.
} 
not superior acceleration at equal or lower cost (batteries not included). The combined effects are summarized in Section 3.1.1. For the purpose of modeling the vehicle and fuel choice decision, it is important to recognize that the weight changes affect vehicle performance regardless of which fuel is used, while the volumetric efficiency, latent heat of vaporization, and octane effects are specific to the fuel being used.

The extra storage tanks of bi-fuel vehicles and the additional volume likely to be required in electric vehicles for battery storage will also likely necessitate compromises in vehicle design. ${ }^{11}$ Modern vehicle designs are carefully optimized to use space efficiently, so that the additional space requirements of gaseous fuel storage are certain to require reduction in carrying capacity. We assume that cargo space rather than passenger space will be sacrificed, and that all of the additional fuel storage volume will translate into lost cargo capacity.

A major reason for promoting alternative fuels is that they will produce social benefits in the form of reduced pollutant emissions and improved energy security. Revealed preference studies of motor fuel purchasing generally indicate that typical consumers will not individually and voluntarily pay to generate these social benefits. However, in several stated preference surveys, consumers say they are willing to pay on the order of 2-5 cents per gallon more for fuels with much lower emissions than conventional gasoline (Golob, et al., 1992). In a recent survey of car owners in New York and California (Setiawan, Hungerford, and Sperling, 1990), roughly $50 \%$ of respondents stated that they would pay $\$ 0.10$ or more for fuels that "produced less air pollution" than gasoline. The consumers were not told in what context they would pay, however (e.g., involuntary tax or voluntary purchase). In our base case, we assume no individual willingness to pay for social benefits. ${ }^{12}$ This assumption can be easily changed, however, to explore other possibilities.

\footnotetext{
${ }^{11}$ DeLuchi, Wang, and Sperling (1989) argue that space savings due to the absence of an exhaust system and pollution control equipment, in conjunction with the smaller size of an electric drivetrain, will totally compensate for the greater volume required for energy storage.

${ }^{12}$ This is not meant to imply no collective willingness to pay. For example, motorists may be more willing to pay for "cleaner fuels" if everyone pays, and thus might support a price subsidy for clean fuels although they would not pay more at the pump on their own initiative if there was no guarantee that others would pay their share.
} 


\subsection{STRATEGY FOR CALIBRATING THE AFVC MODEL}

In the following section we describe how the vehicle and fuel characteristics we have considered are transformed into coefficients of the AFVC model. Only the general methodology is described here. The key steps in the calibration process are,

1. Specify the Characteristics of Alternative Fuels and Vehicles,

2. Specify the Value per Unit for each Characteristic,

3. Estimate a "Generalized Cost" as a Sum of the Dollar Value of AFV Characteristics, Plus Initial Costs (all in \$/bbl gasoline equivalent),

4. Specify the Sensitivity of the Fuel and Vehicle Choice Decisions to Prices, and

5. Transform the Values of Characteristics and Elasticities into MNL Model Coefficients ${ }^{13}$

All costs are converted to units of 1990 dollars per barrel of gasoline equivalent, present value. The costs and values of fuel-specific variables are most naturally expressed in terms of dollars per gallon of gasoline equivalent. Most vehicle specific variables, on the other hand, will be in terms of dollars per vehicle, initial cost. The AFTM requires the logit model to determine the shares as a function of dollars per barrel of gasoline equivalent. It is therefore necessary to transform both vehiclespecific and fuel-specific costs into dollars per barrel of gasoline equivalent. This is done by multiplying initial costs by an annual capital charge rate and dividing by the average annual fuel consumption of a conventional gasoline vehicle in barrels of gasoline, and multiplying costs per gallon of gasoline equivalent by 42 (gal/BBL). The result is a generalized cost, in dollars per barrel of gasoline equivalent, for each fuel (in the case of fuel choice) or each vehicle type (in the case of vehicle type choice).

To derive the MNL model coefficients the AFTM requires, the sensitivity of fuel choice to price must be specified. This is done by assuming price elasticities for the fuel and vehicle choice decisions, based on judgment informed by previous studies of fuel and vehicle type choice. A model to predict future choices among commodities that are not yet readily available cannot be calibrated to data on actual choices. As a result, we cannot be sure that the values we choose will be correct in the sense that they can be shown to be consistent with the real world. Thus, it is prudent to test the sensitivity of the model's predictions to key assumptions. Chapter 5 contains an analysis of the sensitivity of vehicle and fuel share predictions to assumptions about price elasticities and attribute values.

\footnotetext{
${ }^{13}$ This last step is optional since the transformation may easily be done within the AFTM model itself.
} 


\section{SPECIFICATION AND VALUATION OF FUEL AND VEHICLE CHARACTERISTICS}

In Section 2 the characteristics that distinguish among alternative fuels were described, and the theory and mathematical form of the nested multinomial logit choice model were presented. This section details the final steps required to complete the Alternative Fuels and Vehicles Choice Model: 1) selection of numerical values for the characteristics of alternative fuels and vehicles, 2) conversion of those characteristics into dollar values (generalized costs), and 3) translation of generalized costs into coefficients of the NMNL model. The following section then explains how these processes have been implemented as a computer spreadsheet program.

In this section the relevant characteristics of alternative fuel vehicles are specified and evaluated in terms of dollars per barrel of gasoline equivalent energy services. With the exception of battery electric vehicles, vehicle characteristics were taken from studies by Bechtold (1993a, 1993b) for the U.S. Department of Energy. Characteristics associated with the consumption of fuel are taken up first, followed by capital charges associated with the purchase of a given type of AFV. In the section on capital costs, the conversion of capital costs into a capital charge per unit of gasoline equivalent energy service is explained.

\subsection{CHARACTERISTICS ASSOCIATED WITH FUEL USE}

Characteristics accounted for as flows include refueling frequency, refueling convenience, fuelspecific performance changes, and the fuel option value for multi-fuel vehicles. Values were not estimated for fuel availability, perceived fuel quality, and social benefits.

\subsubsection{Refueling Costs}

The cost of greater refueling frequency due to decreased on-board energy storage capability is assumed to be the value of the additional time required. The relative increase in refueling $(R)$ is computed by dividing the energy content of gasoline $\left(E_{g}\right)$ by the energy content of the alternative fuel $\left(\mathrm{E}_{\mathrm{j}}\right)$ times one plus its efficiency gain or loss $\left(\mathrm{e}_{\mathrm{j}}\right)$. This is then multiplied by the ratio of gasoline tank size $\left(Q_{g}\right)$ to alternative fuel tank size $\left(Q_{j}\right)$, in physical units. 


$$
R=\frac{E_{g}}{E_{j}\left(1+e_{j}\right)}\left(\frac{Q_{g}}{Q_{j}}\right)
$$

Estimated percent increases in refueling frequency $([R-1] \times 100)$ and supporting data are shown in tables below. To obtain the cost increase in terms of dollars per gallon, we multiply the increase in relative refueling minus one (R-1), times the average refueling time for that fuel $\left(T_{j}\right)$, times the assumed value of time $\left(\mathrm{V}_{j}\right)$, and divide this number by the assumed fuel purchase quantity $\left(\mathrm{Q}_{\mathrm{j}} \cdot \mathrm{r}\right)$, where $r$ is the typical fraction of the tank that is replaced during refueling. This gives additional cost in dollars per unit of alternative fuel (usually per volumetric gallon). This is converted to dollars per gallon of gasoline equivalent energy by multiplying by $E_{g} /\left[E_{j} \cdot\left\{1+e_{j}\right\}\right]$.

$$
C_{R}=\frac{(R-1) T_{j} V_{j}}{Q_{g} r}
$$

Refueling convenience is represented as in increase in refueling time per event. This is computed as the difference between the alternative fuel refueling cost per gasoline equivalent gallon, minus the gasoline refueling cost per gallons delivered.

$$
C_{D}=\frac{T_{j} V_{j}}{Q_{g} r}-\frac{T_{g} V_{g}}{Q_{g} r}
$$

The sum of equations (3.2) and (3.3) gives the total difference in refueling costs for a gasoline equivalent gallon of the alternative fuel in comparison to gasoline.

Available evidence suggests that the fuel economy of flexible and bi-fuel vehicles will be nearly identical to that of conventional gasoline vehicles. A $1 \%$ fuel economy gain is assumed for fuel flexible methanol and ethanol vehicles using alcohol versus their fuel economy using gasoline (McNutt, 1993). Bi-fuel CNG and LPG vehicles using gasoline are assumed to achieve equal fuel economy, except for the weight penalty attributable to their extra fuel storage tanks. For CNG vehicles this increase will be in the range of $4-5 \%$, and for LPG vehicles $3-4 \%$, for fuel economy losses of about $3 \%$ and $2 \%$, respectively (Bechtold, 1993a, Table 8 ; we assume a $1 \%$ increase in weight reduces MPG by $0.7 \%$ ). Dedicated gaseous fueled vehicles are assumed to achieve the same MPG as a conventional gasoline vehicle. The alcohol flexible vehicle (M85 or E85) is assumed to achieve a $5 \%$ fuel economy advantage (McNutt, 1993). Electric vehicles should be about three times as energy efficient as conventional gasoline vehicles, when energy use is measured in $\mathrm{kWh}$ 
from the electrical outlet and the extra weight of the battery system is taken into account. ${ }^{14}$ The assumptions and calculations underlying this estimate are shown in Table 3.1. The energy storage requirements, battery requirements, gross vehicle weight, and realized energy efficiency, shown in Table 3.1 (bold numbers) have been computed iteratively based on desired range, power train efficiency, battery characteristics, and typical depth of discharge. Assumptions about electric vehicles differ somewhat from those about internal combustion engine (ICE) vehicles. ICE vehicles are assumed to achieve 21.3 MPG on the road, which includes a shortfall of $30 \%$ from federal test cycle fuel economy. We assume that EVs will have regenerative braking, will have no idling losses, and will not travel at the same highway speeds. Their on-road correction has been therefore adjusted to only $10 \%$. As a result, if a conventional vehicle achieves $21.3 \mathrm{MPG}$ in actual use, a comparable EV will attain the equivalent of 27.4. In terms of miles per gallon of gasoline equivalent energy, however, the EV does much better due to its inherently more efficient (5.5 times) powertrain. Miles/kWh are computed by multiplying 27.4 MPG by 5.5 , then multiplying by the ratio of Btu/kWh to Btu/gallon and finally correcting for the efficiency loss an EV suffers due to the additional weight of its batteries. Since this loss is not known until the weight of batteries relative to the weight of the vehicle is known, miles/kWh must be computed iteratively.

The calculations in Table 3.1 proceed as follows. First, energy storage required to achieve the desired 100 mile operating range is computed. Second, the weight of batteries required for the necessary energy storage is computed, and vehicle weight is revised. Third, energy efficiency is adjusted due to the increase in weight, requiring a recalculation of energy storage and battery requirements. Calculations are made iteratively until convergence is reached. Finally, the cost of the required batteries is computed.

"Efficiency" in Table 3.1 is the product of MPG, the "Relative Powertrain Efficiency" of the EV, one minus the "Net Efficiency Loss Due to Weight" times the ratio of Btu/kWh to Btu/gal. of gasoline. Here the lower heating value of gasoline is used for comparability to the energy available for useful work in a kWh of electricity. The "Energy Required" equals the "Desired Range" divided by the "Depth of Discharge" (the nominal or maximum range) divided by "Efficiency." The volume and weight of energy storage is computed by dividing "Energy Required" by the appropriate "Energy Density." Because an EV without batteries is lighter than a conventional vehicle by about $10 \%$, the average vehicle weight is first adjusted downward before the weight of batteries is added. The weight of additional structural support for the batteries is then added to give total gross EV weight.

\footnotetext{
${ }^{14}$ Considering the overall efficiency of primary energy conversion to electricity at the outlet of $30 \%$, battery electric vehicles are close to conventional gasoline vehicles in terms of primary energy efficiency.
} 
Table 3.1 Estimation of Battery Electric Vehicle Characteristics

\begin{tabular}{|c|c|c|c|c|}
\hline Desired Range & 100 & EV MPG & $\mathrm{Btu} / \mathrm{kWh}$ & Gasoline \\
\hline Efficiency (mi/kWh) & 3.99 & 27.4 & 3412 & MPG \\
\hline Depth of Discharge & 0.75 & MPGEG & Btu/Gal & 21.31 \\
\hline Charger Efficiency & 0.90 & From Outlet & 115400 & In-Use \\
\hline Battery Efficiency & 0.75 & 91.1 & & Factor \\
\hline Relative Powertrain Efficiency & 5.50 & Rel. Eff. & & Gasoline \\
\hline Battery Energy Density (wh/kg) & 80.0 & $428 \%$ & & $70 \%$ \\
\hline Volumetric Energy Density (wh/l) & 150.0 & & & In-Use \\
\hline Net Energy Storage Required $(\mathrm{kWh})$ & 33.4 & 1.0 gals. gasoline & & Factor \\
\hline Gross Energy Storage Req. (kWh) & 53.7 & & & EV $90 \%$ \\
\hline Energy Storage Required (kg) & 417.7 & 919.0 lbs. & & \\
\hline Energy Storage Required (l) & 222.8 & 58.9 gals. & & \\
\hline Initial Vehicle Weight & 1609 & 3539 lbs. & & \\
\hline EV Weight Reduction (minus & $10.0 \%$ & & & \\
\hline battery) & 1866 & & & \\
\hline EV Gross Weight (incl. battery) & 0.07 & & & \\
\hline Additional Structural Support (lb/lb) & 1883 & 4104 lbs. & & \\
\hline EV Gross Weight (incl. battery) & $17.1 \%$ & & & \\
\hline Net Increase in Weight (\%) & $10.5 \%$ & & & \\
\hline \multicolumn{5}{|l|}{$\begin{array}{l}\text { Net Efficiency Loss due to Weight } \\
(\%)\end{array}$} \\
\hline Estimated OEM Battery Cost & $\$ 110$ & & & \\
\hline$(\$ / \mathrm{kWh})$ & $50 \%$ & & & \\
\hline Estimated OEM to Retail Markup & $\$ 5,514$ & & & \\
\hline Estimated Battery Cost & $(\$ 500)$ & & & \\
\hline $\begin{array}{l}\text { Cost Difference of EV (minus } \\
\text { battery) }\end{array}$ & $\$ 5,014$ & & & \\
\hline \multicolumn{5}{|l|}{ Net Cost Difference of EV } \\
\hline Estimated Recharging Time (hrs.) & 6 & & & \\
\hline
\end{tabular}

Sources: DeLuchi, Wang, and Sperling, 1989; Automotive Engineering, 1992.

"Net Efficiency Loss due to Weight" is computed assuming an elasticity of energy efficiency with respect to weight of -0.7 . Once convergence has been achieved with respect to weight and efficiency, the cost of batteries is computed. Here we assume $\$ 110 / \mathrm{kWh}$ production cost and a $50 \%$ retail markup. We subtract $\$ 500$ from this estimate to account for the otherwise lower cost of an EV without batteries. 
The relative efficiency factor to be entered in the AFVC model "Refueling" spreadsheet (see Section 4.2) is the MPG in energy equivalent gasoline gallons energy from the electrical outlet, divided by the gasoline MPG, not the EV MPG $(91.1 / 21.3=4.28$ or $428 \%)$. The relevant energy storage value for the AFVC "Refueling" spreadsheet is the "Gross" rather than the "Net" energy storage requirement ( $53.7 \mathrm{kWh})$. The "Gross value accounts for charger and battery efficiency losses and thus represents energy required from the outlet rather than from the battery. It also adjusts for the difference between the higher heating values for fuels used in the AFVC spreadsheets and the lower heating value used here.

The lower energy densities of alternative fuels and the need for dual fuel storage systems in bi-fuel vehicles result in reduced operating ranges for some alternative fuels and thus increased frequencies of refueling. With the exception of EVs, all energy storage capacities for AFVs are given in terms of gallons of gasoline equivalent energy (Table 3.2). CGVs, BiFNGVs, and BiFLPGVs are all assumed to be equipped with 15.4 volumetric gallon fuel tanks. FFVs are assumed to have $18 \mathrm{vol}$. gallon tanks, enabling them to store 10.2 GEG of M85 and 12.8 GEG of E85. Bi-fuel CNG vehicles are assumed to have only 5.2 GEG of CNG storage capacity, while BiFLPGVs will be able to store 14.6 GEG due to the relatively high energy density of LPG stored in liquid form.

Refueling times are derived from those presented in Bechtold (1993a), except that it is not assumed that owners of bi-fuel vehicles will always refuel both storage systems simultaneously. Bechtold (1993) assumes that bi-fuel operators will use up their gaseous fuel, switch to gasoline, and refuel after using $25 \%$ of their gasoline storage. This places a strong constraint on the relative shares of natural gas and gasoline consumed by these vehicles which is contrary to the economic theory of fuel choice underlying the AFVC Model. Instead, it is assumed that either fuel will be used independently, and that simultaneous refueling will not be possible. It is assumed, however, that essentially all of the alternative fuel will be used by bi-fuel vehicles before refueling and that little or no reserve will be maintained. Bechtold (1993a) assumes that all other vehicles will maintain a 90 mile reserve, approximately $1 / 4$ tank and that assumption is made here, except for electric vehicles which are assumed to have a practical range of 100 miles when recharging at $25 \%$ of full battery charge.

The above assumptions are used to compute the time cost of refueling, assuming time spent refueling is valued at $\$ 10$ /hour for all vehicles except $E V s$, for which it is valued at $\$ 1.00$ per hour. The value of time for EV refueling is highly uncertain. Clearly, time spent recharging by slow recharge methods that require on the order of six hours for a complete recharge, is qualitatively different from the few minutes spent refueling a conventional vehicle. One is a sizable block of time 
Table 3.2 Alternative Fuel Vehicle On-Board Fuel Storage Capacities and Refueling Times

\begin{tabular}{lcc}
\hline \multicolumn{1}{c}{ Vehicle \& Fuel Type } & $\begin{array}{c}\text { Tank Size } \\
\text { (GEG) }\end{array}$ & $\begin{array}{c}\text { Refueling Time } \\
\text { (Min) }\end{array}$ \\
\hline Conventional Gasoline & 15.4 & 6 \\
FFV & & \\
$\quad$ Gasoline & 18.0 & 6.5 \\
M85 & 10.2 & 6.5 \\
E85 & 12.8 & 6.5 \\
Bi-Fuel NGV & & \\
Gasoline & 15.4 & 6.0 \\
CNG & 5.2 & 8.0 \\
Bi-Fuel LPG & & \\
Gasoline & 15.4 & 6.0 \\
LPG & 14.6 & 6.5 \\
Dedicated CNG & 10.4 & 8 \\
Dedicated LPG & 15.4 & 6.5 \\
Alcohol Flexible Vehicle & & 6.5 \\
M85 & 10.2 & 6.5 \\
E85 & 12.8 & \\
\hline
\end{tabular}

that allows other activities (sleeping, working) to take place simultaneously while the other demands nearly full attention for its brief duration. Past studies have viewed this battery EV characteristic as a limitation on the vehicle's capabilities, rather than a cost for time (e.g., Charles River Assoc., Inc., 1981; Beggs and Cardell, 1980; Train, 1980). Nonetheless, the long recharging times assumed here definitely impose a nontrivial cost, and the values we have assumed appear to be plausible though very uncertain.

\subsubsection{Fuel Option Value for Multi-Fuel Vehicles}

In a static equilibrium model such as the AFTM, there is only one price for each fuel. Thus, a fuel is unambiguously cheaper, equal in price, or more expensive than another. In reality, fuel prices fluctuate over time, so that a fuel that is on average more expensive may occasionally be cheaper. Flexible fuel vehicle owners have an option to select whichever fuel is cheapest at any time. This gives flexible fuel vehicles a cost advantage over single fuel vehicles that is not reflected in any other variable in the vehicle choice model. Whether or not such an option value should be included 
in a static equilibrium model is an open question. At the very least, it requires a reinterpretation of the static equilibrium framework. Perhaps the most straightforward is to interpret the prices of an AFTM forecast as expected values of prices which are actually random variables. ${ }^{\text {is }}$ Under this assumption, the fuel price for a single fuel vehicle is adequately captured by its expected value, but the fuel price for a flexible fuel vehicle is not, since the owner has an option to select the cheaper fuel at any given time.

Consider a set of $T$ pairs of fuel prices (indexed $t$ ) for the conventional and an alternative fuel $\left\{\mathrm{p}_{\mathrm{ct}} \mathrm{p}_{\mathrm{at}}\right\}$. Suppose we divide this set into two parts, a subset $\mathrm{C}$ which contains all the pairs for which the conventional fuel is cheaper $\left(p_{c t}<p_{a t}\right)$, and a subset $A$ defined by $p_{a t}<p_{c t}$. The average prices for the fuels are,

$$
p_{c}=\frac{1}{T} \sum_{t=1}^{T} p_{c t} \quad, \quad p_{a}=\frac{1}{T} \sum_{t-1}^{T} p_{a t}
$$

Assume that pairs were generated in such a way that each pair is equally likely to occur (i.e., the pairs are random). ${ }^{16}$ The relative frequency (or probability density) associated with each pair is therefore $1 / \mathrm{T}$.

We define the option value of the flexible fuel combination $[c, a]$ as,

$$
\Delta=\frac{1}{2}\left\{\sum_{C} \frac{1}{T}\left(p_{a t}-p_{a t}\right)+\sum_{A} \frac{1}{T}\left(p_{a t}-p_{a t}\right) \pm\left(p_{c}-p_{a}\right)\right\rceil
$$

Where the \pm indicates that the difference in means $\left(p_{c}-p_{a}\right)$ will be subtracted if $p_{a}>p_{c}$ and added otherwise. We substitute the average price equations (3.4) into equation (3.5), separating the summation over $T$ into two parts corresponding to the sets $C$ and $A$.

$$
\Delta=\frac{1}{2 T}\left\lceil\sum_{C}\left(p_{a t}-p_{c t}\right)+\sum_{A}\left(p_{c t}-p_{a t}\right) \pm\left[\sum_{C}\left(p_{a t}-p_{a t}\right)+\sum_{A}\left(p_{c t}-p_{a t}\right)\right]\right]
$$

\footnotetext{
${ }^{15}$ This interpretation further requires that decision-makers are risk neutral to avoid having to consider the distributions of variables in computing an equilibrium solution.

${ }^{16}$ Another notion is that the pairs represent a time series of prices.
} 
Combining and canceling terms gives the average price advantage of being able to buy the cheapest fuel in comparison to a single fuel vehicle using the cheaper of the two fuels. If we assume that $p_{a}>p_{c}$, then we should subtract the term in square brackets. The two terms involving summation over A will cancel so that the option value is,

$$
\Delta=\frac{1}{T} \sum_{C}\left(p_{a t}-p_{c t}\right)
$$

An interesting result that follows from the above is that the average price reduction available with a flexible fuel vehicle versus a single fuel vehicle which uses the fuel with the lowest average price is exactly equal to the average price reduction attainable with a flexible fuel vehicle versus a single fuel vehicle which uses the fuel with the highest price minus the average price advantage of the fuel with the lower average price. Thus, in comparison to a single fuel vehicle using the low price fuel, the option value of the flexible fuel vehicle is $\Delta$. In comparison to the single fuel vehicle using the higher priced fuel, the multi-fuel vehicle's option value is $\Delta+\left(p_{c}-p_{a}\right)$. The difference in average prices is taken into account in the nested multinomial logit choice model, which is a function of average prices. The utility of a single fuel vehicle using the higher priced fuel is computed using that higher price and thus reflects its greater average cost. For the fuel flexible vehicles, both prices are used in computing the logsum value, but the prices are assumed to be constant. The NMNL model treats the average prices as if they were constant prices (i.e., as if there were a static equilibrium). Using the assumptions stated above, the option value term, $\Delta$, accounts for the fact that prices are not constant.

Estimation of the fuel option value for flexible and bi-fuel vehicles is based on fuel prices estimated by the AFTM, together with assumed price distributions based on an analysis of historical price series. For each multi-fuel vehicle, fuel prices are assumed to follow a bivariate normal probability distribution. ${ }^{17}$ The bivariate normal distribution is specified by the mean prices of the two fuels $\left(\mu_{\mathrm{g}}, \mu_{\mathrm{a}}\right)$, their standard deviations $\left(\sigma_{\mathrm{g}}, \sigma_{\mathrm{a}}\right)$, and the correlation of their prices $(\rho)$. The integral over the region where $\mathrm{p}_{\mathrm{a}}<\mathrm{p}_{\mathrm{g}}$ of the product of the price difference $\left(\mathrm{p}_{\mathrm{g}}-\mathrm{p}_{\mathrm{a}}\right)$ and the bivariate normal density function $\left(f\left\{\mu_{g}, \mu_{a}, \sigma_{g}, \sigma_{a}, \rho\right\}\right)$ gives the expected advantage of being able to buy the alternative fuel whenever it is cheaper. Similarly, integrating the product of $\left(f\left\{\mu_{g}, \mu_{g}, \sigma_{g}, \sigma_{a}, p\right\}\right)$ and $p_{a}-p_{g}$ whenever gasoline is cheaper, gives the expected advantage of the option to buy gasoline when it is cheaper.

\footnotetext{
${ }^{17} \mathrm{~A}$ trivariate normal distribution of gasoline, ethanol, and methanol prices would be most appropriate for FFVs. Because this greatly complicates the spreadsheet implementation, and because the option value for ethanol versus gasoline or methanol is approximately zero, we use a bivariate distribution based on methanol and gasoline prices to compute the option value for FFVs.
} 
Subtracting the expected price difference between the two fuels from the sum of the two integrals gives the advantage of having the option to buy cheaper fuel as prices vary, over using the fuel with the lowest average price all the time. We define this difference as the option value of the FFV.

$$
\Delta=\frac{1}{2}\left(\int_{p_{a}=0}^{p_{c}} f\left(\mu_{c} \mu_{a} \sigma_{c} \sigma_{a} \rho\right) \cdot\left(p_{c}-p_{a}\right) \partial p_{c} \partial p_{a}+\int_{p_{c}=0}^{p_{a}} f\left(\mu_{c} \mu_{a} \sigma_{c} \sigma_{a} \rho\right) \cdot\left(p_{a}-p_{c}\right) \partial p_{a} \partial p_{c}-\left|p_{c}-p_{a}\right|\right)
$$

We compute the option value by numerical integration of a specified density function. We use predicted prices as the mean price parameters of $f$. Values of $\rho$ and $\sigma$ have been chosen based on an analysis of annual fuel prices from 1978 to 1992 (Figure 3.1). For liquid fuels, representative values of the parameters appear to be $\rho=0.9$ or higher, and $\sigma_{\mathrm{a}}$ and $\sigma_{\mathrm{g}}$ equal to $25-30 \%$ of the mean (Table 3.3). Gaseous fuels (propane, commercial natural gas, and residential natural gas) are highly correlated with each other ( $\rho \approx 0.9$ ) but much less strongly correlated with the prices of liquid fuels ( $\rho$ values range from 0.22 to 0.66 ). In addition, the variation in prices of gaseous fuels has been lower, standard deviations being on the order of $15 \%$ of the mean. No doubt, this is partly attributable to historical regulation of the natural gas market. Strictly on the basis of these historical data, one would choose $\sigma \approx 0.3$ and $\rho \approx 0.95$ for liquid fuels, and $\sigma \approx 0.15$ and $\rho \approx 0.5$ for gaseous fuels. However, there is reason to expect that correlations among prices would be more similar to those of liquid fuels given a substantial transportation fuel market for gaseous fuels. It is also possible that gaseous fuel prices could be come more volatile in the future in the absence of price regulation.

In general, the closer the mean prices, the larger the standard deviations, and the smaller the correlation between their prices, the larger the option value will be. Example options values and key assumptions are presented in Table 3.4.

Strictly speaking, option values should be determined simultaneously with the overall market equilibrium for fuels. Option values tend to be small relative to mean prices, however, so that changing the option values will have little effect on the world equilibrium energy prices. This suggests that if prices from an initial run excluding option prices are used to compute the option prices and then the new AFVC model coefficients are substituted into the AFTM and it is rerun, further iteration will not be necessary. Initial experimentation has borne this out: changes in world fuel prices on a second iteration have been $\$ 0.01$ per barrel or smaller. 


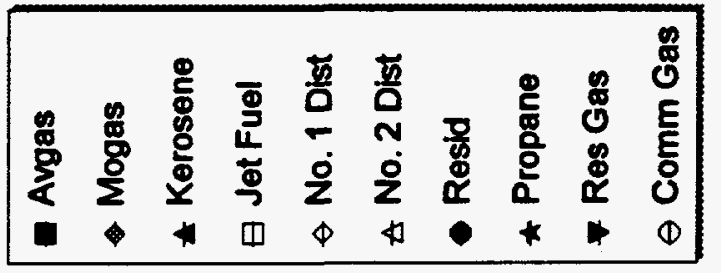
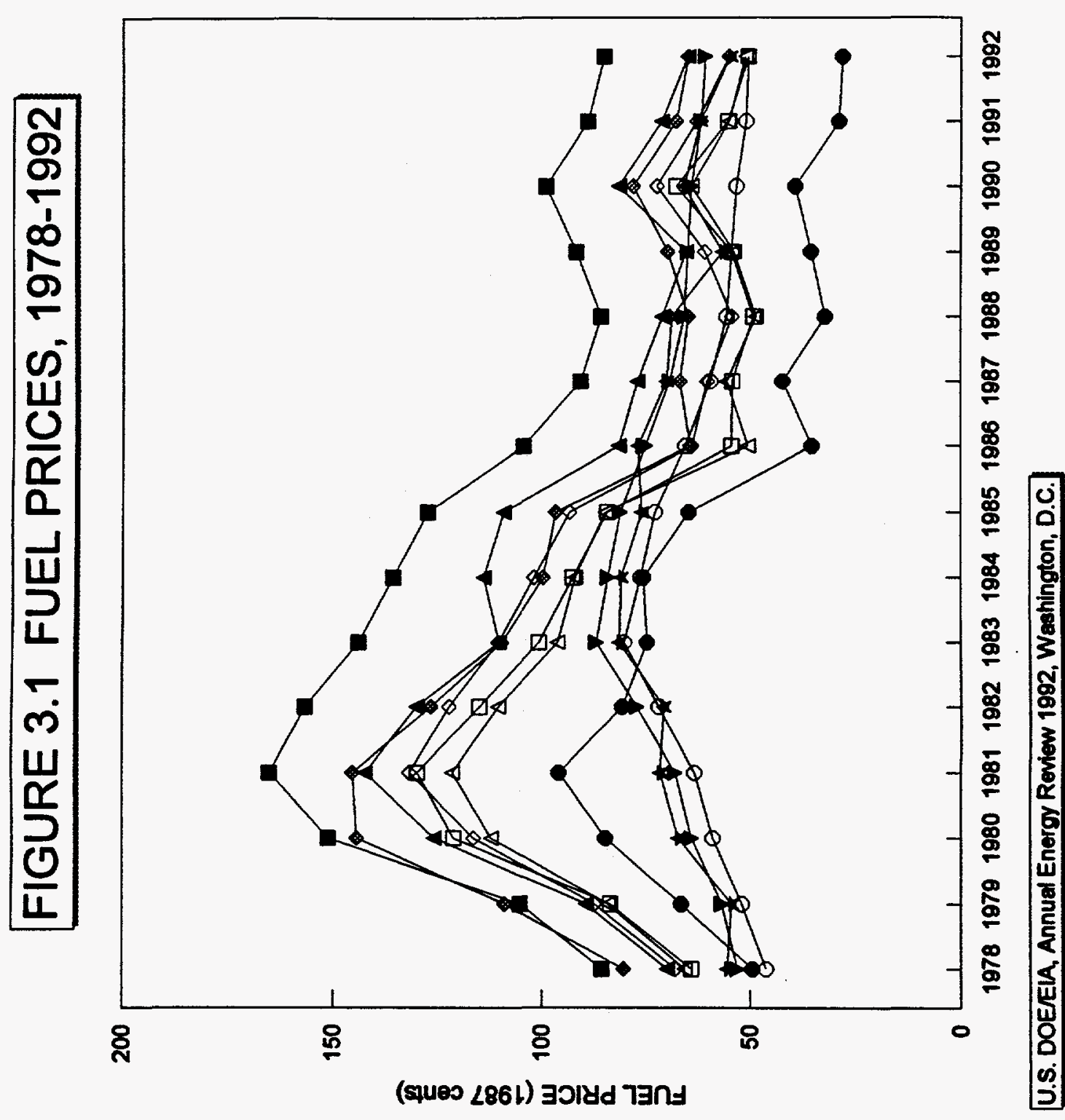
Table 3.3 Variation and Correlation Among Fuel Prices, 1978-1992

\begin{tabular}{|c|c|c|c|c|c|c|c|c|c|}
\hline $\begin{array}{l}\text { Aviation } \\
\text { Gasoline }\end{array}$ & $\begin{array}{l}\text { Motor } \\
\text { Gasoline }\end{array}$ & Kerosene & $\begin{array}{l}\text { Jet } \\
\text { Fuel }\end{array}$ & $\begin{array}{l}\text { No. } 1 \\
\text { Distillate }\end{array}$ & $\begin{array}{c}\text { No. } 2 \\
\text { Distillate }\end{array}$ & Oil & Propane & $\begin{array}{l}\text { Residential } \\
\text { Nat. Gas }\end{array}$ & $\begin{array}{l}\text { Commercial } \\
\text { Nat.Gas }\end{array}$ \\
\hline \multicolumn{10}{|c|}{ Mean } \\
\hline 114.4 & 92.5 & 93.5 & 78.5 & 84.0 & 76.4 & 55.6 & 67.5 & 5.51 & 4.87 \\
\hline \multicolumn{10}{|c|}{$\begin{array}{c}\text { Standard Deviation } \\
\text { (Coefficient of Variation) }\end{array}$} \\
\hline $\begin{array}{l}29.1 \\
(25 \%)\end{array}$ & $\begin{array}{l}29.0 \\
(31 \%)\end{array}$ & $\begin{array}{l}26.0 \\
(28 \%)\end{array}$ & $\begin{array}{c}27.7 \\
(35 \%)\end{array}$ & $\begin{array}{c}26.6 \\
(32 \%)\end{array}$ & $\begin{array}{c}25.3 \\
(33 \%)\end{array}$ & $\begin{array}{c}23.0 \\
(41 \%)\end{array}$ & $\begin{array}{c}9.2 \\
(14 \%)\end{array}$ & $\begin{array}{c}0.80 \\
(14 \%)\end{array}$ & $\begin{array}{c}0.83 \\
(17 \%)\end{array}$ \\
\hline \multicolumn{10}{|c|}{ Correlation Coefficients } \\
\hline Av Gas & 0.92 & 0.99 & 0.96 & 0.98 & 0.95 & 0.93 & 0.58 & 0.57 & 0.71 \\
\hline Mo Gas & & 0.93 & 0.99 & 0.96 & 0.98 & 0.96 & 0.26 & 0.22 & 0.41 \\
\hline Kerosene & & & 0.97 & 0.98 & 0.96 & 0.95 & 0.57 & 0.52 & 0.67 \\
\hline Jef Fuel & & & & 0.99 & 0.99 & 0.97 & 0.39 & 0.35 & 0.53 \\
\hline No. $1 \mathrm{D}$ & & & & & 0.99 & 0.97 & 0.47 & 0.45 & 0.62 \\
\hline No. $2 \mathrm{D}$ & & & & & & 0.98 & 0.37 & 0.36 & 0.58 \\
\hline Resid. & & & & & & & 0.43 & 0.40 & 0.58 \\
\hline Propane & & & & & & & & 0.91 & 0.90 \\
\hline Res. Gas & & & & & & & & & 0.97 \\
\hline
\end{tabular}


Table 3.4 Estimated Option Values for Pairs of Alternative Fuels and Gasoline (Prices in $1990 \$$ per gallon)*

\begin{tabular}{lllll}
\hline & Fuel & Expected Price & $\begin{array}{c}\text { Expected Price } \\
\text { Difference v. } \\
\text { Gasoline }\end{array}$ & \multicolumn{2}{c}{$\begin{array}{c}\text { Net Expected Value } \\
\text { of Multi-Fuel Option } \\
(\$ / \text { gal })\end{array}$} & $(\$ /$ bbl $)$ \\
\hline M85 & $\$ 48.04$ & $-\$ 4.18$ & $\$ 0.018$ & $\$ 0.76$ \\
E85 & $\$ 72.52$ & $\$ 20.30$ & $\$ 0.001$ & $\$ 0.04$ \\
CNG & $\$ 64.88$ & $\$ 12.66$ & $\$ 0.003$ & $\$ 0.13$ \\
LPG & $\$ 49.15$ & $-\$ 3.07$ & $\$ 0.026$ & $\$ 1.09$ \\
\hline
\end{tabular}

Assumes a correlation of 0.9 and coefficient of variation of 0.25 for each fuel.

\subsection{CAPITALIZED VALUES}

Certain alternative fuel characteristics are inherently capital charges. The incremental cost of AFV technology is the most obvious example. Other characteristics are most readily evaluated as capital costs (or values) because of the nature of the information available on the value consumers attach to them. Changes in performance and the cost of cargo capacity converted to fuel storage fall into this category. Despite the fact that performance is experienced over time as the vehicle (and fuel) are used, most information comes from studies of motor vehicle demand and is expressed in terms of dollars per vehicle, initial price equivalent. All capital costs must be converted into dollars per barrel of gasoline equivalent energy service in order to be consistent with the AFTM methodology. How this is done using the concept of a capital charge rate is explained below. Next, incremental costs of AFVs are discussed, followed by performance changes and the effects of fuel storage on cargo capacity.

\subsubsection{Estimation of Capital Costs per Barrel of Gasoline Equivalent}

Characteristics of the elementary choices (the fuel and vehicle combinations illustrated in Figure 1.1) can be divided into two types: 1) those associated with the use of a particular fuel that are experienced by the consumer only when that fuel is used, and 2) those associated with a vehicle that are experienced whenever the vehicle is used, regardless of which fuel powers it. Because the prices that drive choices in the AFTM model are the prices of fuels expressed in dollars per barrel of gasoline energy equivalents (BGE), both fuel and vehicle characteristics must be valued in terms 
of dollars per BGE. For characteristics that can be naturally expressed in terms of dollars per gallon (or $\$$ per energy unit) this can be done by simply multiplying by 42 . Characteristics that are more naturally expressed as capital costs (e.g., incremental vehicle cost) must be converted into dollars per barrel. This is done using a levelized cost method to compute a capital charge rate per barrel of gasoline equivalent energy service.

Assume that a vehicle purchaser expects to own a vehicle for a period of $Y=4$ years, at which time he will resell. Let the cost of the vehicle be $C$, the depreciation rate for automobiles be $\delta \approx 0.15$ $(15 \% / y r$.), and the real interest (or discount) rate be $\mathrm{i}=0.07(7 \%)$. The cost of the investment to the purchaser is the initial capital cost minus the present value of the resale price. The annual cost, $\mathrm{C}_{0}$, is given by,

$$
\int_{0}^{Y} C_{0} e^{-t t} d t=C-\left(C e^{-(i, \delta) Y}\right)
$$

Solving this for the capital charge rate $\mathrm{R}=\left(\mathrm{C}_{\mathrm{o}} / \mathrm{C}\right)$, we get,

$$
\frac{C_{o}}{C}=i \frac{\left(1-e^{-(i \cdot \delta) Y}\right)}{\left(1-e^{-i Y}\right)}
$$

which, if we plug in the above assumptions for $i, \delta$, and $Y$, gives an annual capital charge rate of $16.8 \%$. We assume that all incremental capital costs (hedonic or financial) of AFVs can be converted to equivalent annual charges in this way.

To obtain an annual charge per barrel of gasoline equivalent energy service, we divide the annual charge by annual fuel consumption. Average annual fuel consumption equals overall miles driven divided by fleet average miles per gallon. The average household vehicle traveled 10,600 miles per year in 1991, according to the latest Department of Energy survey (U.S. DOE/EIA, 1993, Table 5). Annual motor vehicle usage has remained in the vicinity of 10,000 miles per year for at least two decades (Davis and Strang, 1993, Table 4.18). Projections to 2010, however, call for vehicle stock to grow at a slower rate than vehicle use, resulting in increased annual miles per vehicle by 2010 . The U.S. Department of Energy (U.S. DOE/EIA, 1993b, Table A-14) projected light duty vehicle annual miles of 11,383 and average fuel economy of 21.3 MPG for the year 2010 giving an average annual fuel consumption of 12.7 barrels of gasoline. ${ }^{18}$ The same capital charge rate and annual

\footnotetext{
${ }^{18}$ Any of these assumptions can be varied in the spreadsheet implementation of this methodology, described below.
} 
barrels of gasoline are used for every fuel type regardless of the actual level of annual energy use required by that particular technology to produce the same number of vehicle miles. That is, the capital charge is therefore a charge per unit of energy service (vehicle miles), rather than per unit of energy use.

\subsubsection{Incremental Costs of AFVs}

FFVs and DFVs require additional fuel metering or fuel storage equipment, and may demand more costly materials. Gaseous fueled vehicles, in particular, require more expensive, space consuming fuel tanks, capable of storing fuels at $3,000 \mathrm{psi}$, or greater. Battery electric vehicles may cost less to manufacture, batteries not included, but the additional cost of batteries is likely to make their initial cost considerably higher than CGVs. Because AFVs are not in full-scale production, there remains considerable uncertainty about their eventual cost differences. Several studies suggest that the incremental costs based on Bechtold (1993a) shown in Table 3.5 provide a reasonable range (Wang, Sperling, and Olmstead, 1993; Interagency Commission on Alternative Fuels, 1990). In some cases, Bechtold (1993a) provides a clear high and low cost estimate. Where he does not, we assume a high cost $33 \%$ higher than his single cost estimate. For AFVs we assume $\$ 100$ as a high estimate cost increment.

Table 3.5 Incremental Initial Cost Estimates for AFVs

\begin{tabular}{lcc}
\hline \multicolumn{1}{c}{ Vehicle Type } & High Estimate & Low Estimate \\
\hline FFV & $\$ 300$ & $\$ 100$ \\
CNG DFV & $\$ 1,111$ & $\$ 817$ \\
LPG DFV* & $\$ 861$ & $\$ 625$ \\
CNG Dedicated & $\$ 600$ & $\$ 451$ \\
LPG Dedicated & $\$ 225$ & $\$ 171$ \\
Alcohol FV & $\$ 100$ & $\$ 0$ \\
Battery EV & $\$ 6,692$ & $\$ 5,019$ \\
\hline
\end{tabular}

*Bechtold (1993a) does not provide a cost estimate for original equipment manufacture (OEM) LPG vehicles. The estimate shown here is obtained by dividing Bechtold's estimated labor costs by two and using his material costs as given.

\subsubsection{Value of Performance Changes}

Performance advantages are specified in terms of an increase in horsepower per pound. Greene and Liu (1988) surveyed more than a dozen models of vehicle type choice and found a wide range of values for acceleration performance. They chose a typical value of $\$ 55 / \mathrm{cid} / 1,000 \mathrm{lbs}$., which they 
equated to $\$ 110 / \mathrm{hp} / 1,000$ lbs. (1985\$). For a typical 1985 vehicle with approximately $35 \mathrm{hp}$ per 1,000 lbs. (Murrell, et al., 1993) this equals $\$ 385$ per $10 \%$ increase in performance (just over $\$ 450$ in 1990 \$). In a stated preference survey of motorists in New York and California, Sperling, Hungerford, and Kurani (1990) found that about 50\% expressed willingness to pay $\$ 0.10 /$ gal., or more, for a $10 \%$ increase in power. For a typical car, this equates to $\$ 250-\$ 300$ in purchase price. Because light duty vehicle performance has been steadily increasing over time and because we assume a decreasing marginal willingness to pay for performance increases, we choose a value of $\$ 25$ per $1 \%$ increase in performance to value the performance differences of AFVs (Table 3.6).

Table 3.6 Power to Weight Changes for Alternative Fuel Vehicles

\begin{tabular}{lccc}
\hline \multicolumn{1}{c}{ Vehicle Type } & $\begin{array}{c}\text { Power } \\
\text { Chang } \\
\text { e }\end{array}$ & Weight Change & HP/WT Change \\
\hline FFV using M85 or E85 & $+6 \%$ & $0 \%$ & $+6 \%$ \\
CNG Passenger Cars & $-10 \%$ & $+4.2 \%$ to $+4.7 \%$ & $-16.0 \%$ to - \\
& & & $16.6 \%$ \\
CNG Light Trucks & $-10 \%$ & $+4.2 \%$ to $+5.9 \%$ & $-16.0 \%$ to - \\
& & & $18.1 \%$ \\
LPG Passenger Cars & $-5 \%$ & $+3.7 \%$ & $-9.3 \%$ \\
LPG Light Trucks & $-5 \%$ & $+3.2 \%$ & $-8.8 \%$ \\
\hline
\end{tabular}

Source: Bechtold, 1993, Tables 7 and 8.

Sperling, et al. claimed that use of methanol in an FFV would give approximately a $10 \%$ increase in power, but this assumes that the FFV has been optimized for methanol, and will therefore run very poorly on conventional gasoline. Perhaps fuel-flexible vehicles will be designed to run somewhat better on alcohol than gasoline, but it is doubtful that anywhere near full advantage can be taken of the roughly 5-6 extra octane points. Similarly, natural gas has an octane rating of 120 . DFVs that must also run well on gasoline could not take advantage of even a small fraction of CNG's additional octane rating without some sort of variable displacement design. To date, no Natural Gas Vehicles (NGV) that we are aware of derive any performance advantage from natural gas' high octane number. Thus, we assume no octane advantage for CNG DFVs.

For CNG BiFNGVs there is also a volumetric displacement penalty, due to the fact that as a gas, CNG displaces air in the cylinder effectively reducing the size of the charge. Since natural gas 
requires an air:fuel ratio of about ten to one for stoichiometry, the effective volumetric reduction is about $10 \%$ (Interagency Commission on Alternative Fuels, 1990). ${ }^{19}$ We assume that the $10 \%$ displacement penalty equates to a $10 \%$ performance penalty (Bechtold, 1993a).

\subsubsection{Value of Cargo Capacity}

The lower energy densities of gaseous fuels and electricity storage in batteries will require that significantly more space be devoted to energy storage for these types of alternative fuel vehicles. In addition, bi-fuel vehicles will require more space for their second fuel system. The shape and size of CNG storage tanks virtually require that they be stored in cargo space. Although innovative solutions to $\mathrm{CNG}$ storage may be developed, we assume that cargo space will be reduced. For bifuel CNG vehicles, we assume that all of the additional CNG storage volume will translate into reduced cargo volume. For dedicated CNG vehicles, we subtract the volume of a conventional gasoline tank from the CNG tank volume to estimate the net loss of cargo space. DeLuchi, et al. (1989) have argued that battery electric vehicles can be designed to accommodate batteries with no loss of passenger or cargo volume due to the reduced size of powertrain components. We subtract the size of a gasoline tank from the estimated required battery volume, then divide the remainder in half to allow for the powertrain advantage of an EV (Table 3.7).

Table 3.7 Loss of Cargo Capacity to Energy Storage in Gaseous-Fueled and Battery Electric Vehicles

\begin{tabular}{lccc}
\hline & $\begin{array}{c}\text { Tank Volume } \\
\text { (gallons) }\end{array}$ & $\begin{array}{c}\text { Net Loss } \\
\text { (gallons) }\end{array}$ & $\begin{array}{c}\text { Net Loss } \\
\text { (cu. ft.) }\end{array}$ \\
\hline Bi-Fuel CNG & 33.3 & 33.3 & 4.5 \\
Dedicated CNG & 68.4 & 49.9 & 6.7 \\
Bi-Fuel LPG & 17.5 & 17.5 & 2.4 \\
Battery Electric & 58.9 & 20.2 & 2.7 \\
\hline
\end{tabular}

Sources: Bechtold, 1993c; Table G, above.

The value of cargo capacity is difficult to pinpoint. Few studies have attempted to estimate it, and those that have, have produced inconsistent results. For example, one recent study found that

\footnotetext{
${ }^{19}$ The volumetric performance loss of CNG dual fuel vehicles is the result of optimizing the engines to run on gasoline. Innovative design, perhaps using variable displacement design, could mitigate the performance loss. Such designs have not been used to date, however.
} 
increasing trunk space actually reduced the likelihood of vehicle purchase for U.S. and European manufacture vehicles and had no effect on the desirability of Japanese vehicles, results the authors termed an "anomalies" (McCarthy and Tay, 1989). In an earlier study, Manski and Sherman (1980) estimated that the value of one additional cubic foot of luggage space was worth between $\$ 44$ and $\$ 238$ (1976 \$), depending on the income and education levels of buyers. Train and Lohrer (1982) estimated marginal values per cubic foot of luggage space of from $\$ 118$ to $\$ 365$ (1978\$), with higher values for larger, higher income households. However, luggage space appeared as a significant variable only in their model for households owning one vehicle. In their multi-vehicle household analysis, luggage space was not a factor. The positive values appear to be high relative to estimates of consumer willingness to pay for passenger volume. In a survey of ten studies and 14 models, Greene and Liu (1988) found a range of typical estimates of from $\$ 26$ to $\$ 156$ (1984 $\$$ ) per cubic foot of interior volume. In light of the facts that, 1) only three studies provide estimates of the value of cargo volume, 2) those that do present estimates are not consistent, ${ }^{20}$ and 3) cargo space should probably be valued at less than passenger space, we choose a value of $\$ 25$ per cubic foot as an estimate of the marginal value of cargo space lost to fuel storage.

\subsection{CALCULATION OF NMNL MODEL COEFFICIENTS}

Six AFV attributes are included in computing AFV-specific constants for the MNL model ${ }^{21}$ :

1. Initial Vehicle Cost

2. Cost of Increased Refueling Due to Range Limitations

3. Cost of Increased Refueling Time

4. Value of Performance Increases or Decreases

5. Value of the FFV Fuel Option

6. Value of Cargo Capacity Lost to Fuel Storage

Seven vehicle types are considered as alternatives to the conventional gasoline vehicle (CGV):

\footnotetext{
${ }^{20}$ Inconsistent parameter estimates across econometrically estimated vehicle choice models is a frequent problem. It appears to result from a combination of factors including the complexity of the vehicle choice decision and the large number of potential variables, the strong correlations among variables associated with vehicle size and luxury features, and the difficulty of formulating a model that takes into account all relevant factors to the diverse population of car buyers.

${ }^{21} \mathrm{An}$ additional option that could be included in the future is estimated maintenance and repair costs. These are likely to differ across alternatives, especially between electric and internal combustion engine vehicles.
} 
1. Flexible Fuel Vehicle (Using M85, E85, or Conventional Gasoline) (FFV)

2. CNG Bi-Fuel Natural Gas Vehicle (BiFNGV)

3. LPG Bi-Fuel Liquefied Petroleum Gases (BiFLPG)

4. CNG Dedicated (NGV)

5. LPG Dedicated (LPGV)

6. Alcohol Flexible (Using M85 or E85) (AFFV)

7. Battery Electric Vehicle (EV)

\subsubsection{Parameter Estimation}

Given the monetary values assigned to vehicle attributes parameters of the NMNL vehicle and fuel choice equations can be calculated by specifying fuel price slope coefficients for the vehicle and fuel choice models. The fuel price slope is estimated by specifying an assumed own price elasticity of demand at a specific market share and initial average vehicle price. It is convenient to use $50 \%$ as the initial market share, although any share percentage could be used. Initial elasticity estimates can be based on previous empirical studies of fuel and vehicle type choice. Given the price slopes, we can compute the alternative fuel intercept terms by multiplying the sum of fuel attribute values in dollars per barrel by the price slope. The price slope is the coefficient that translates dollars per barrel into the utility measure of the MNL model, $\mathrm{U}_{\mathrm{i}}$. Its units must therefore be "utils" per dollar. Multiplying the dollar value of nonvariable attributes by the price slope similarly transforms dollars into the MNL constant term (in utils).

In the multinomial logit model, the elasticity $\left(\beta_{i}\right)$ of market share $\left(s_{i}\right)$ for choice $i=1,2$ with respect to price (p) is,

$$
\beta_{i}=b p_{i}\left(1-s_{i}\right)
$$

By rearranging, we can compute the MNL price slope parameter $b$.

$$
b=\frac{\beta_{i}}{p_{i}\left(1-s_{i}\right)}
$$

Thus, if we know or assume an elasticity at an arbitrary market share (e.g., 50\%) and base price (say, $\$ 55 / \mathrm{bbl}$ ), we can compute b directly from equation (3.11). Given a value for $\mathrm{b}$, we can calculate the MNL model constants, $A_{i}$, as the product of $b$ and the sum of option i's attribute values $\left(\Sigma_{k} C_{k}\right)$. 


$$
A_{i}=b \sum_{k=1}^{n} C_{i k}
$$

Two recent studies of motor gasoline demand both indicate that the price elasticity of demand for similar motor fuels is very large. In a study of choice among premium leaded, regular leaded, premium unleaded, and regular unleaded gasolines, Greene (1989) estimated price elasticities at $50 \%$ market share of -15 to -20 , for the years $1982-85$. Using a different data set and estimation method, Phillips and Schutte (1988) estimated own price elasticities (at the mean values for their sample) for demand for full vs. self-service gasoline of -35 to -40 . This evidence suggests that if FFV owners perceive gasoline and alternatives to be much like different grades or service levels of gasoline, demand will be very price elastic. Much lower elasticities of alternative fuel choice were obtained by Golob, et al. (1992) and Bunch, et al. (1993) using the California Energy Commission's recent stated preference survey. Using an estimated fuel cost per mile of 8 cents per mile (the average of the choices described to respondents) the elasticity of fuel choice for a multifuel vehicle would be about -3 . This is three times as large as the elasticity of vehicle choice (about -1 at $50 \%$ share and average price) obtained in the same survey. Thus, the CEC stated preference survey results tend to confirm the belief that fuel choice is much more elastic than vehicle choice, which is consistent with the nested choice structure used here. The stated preference elasticities, however, are much smaller than those found in revealed preference studies of gasoline grade choice. Two reasons for this difference may be the fact that gasoline grades are more similar than alternative fuels for multi-fuel vehicles, and that the hypothetical stated choice situation gives greater importance to unobserved attributes. The more dissimilar the fuels are, the lower the own price elasticity should be. Thus, the choice between gasoline and compressed natural gas should be less price elastic than the choice between premium and regular grade gasoline. The derivation of the logit model in Appendix A shows that the variance of the random error term representing unobserved attributes in the MNL model is inversely related to the price elasticity. In a hypothetical choice, stated preference survey more is left to the respondent's imagination and so the importance of unobserved attributes is very likely to be exaggerated relative to a real-world choice situation in which the options are familiar.

Numerous studies have estimated the price sensitivity of vehicle type choice decisions. In nearly all, however, the choice is among passenger cars or light duty vehicles of all types, large and small, luxury and economy. The AFVC model assumes that consumers are choosing among vehicles that are virtually identical, except for characteristics related to alternative fuels. Perhaps the best 
analogy for this situation comes from a study of the choice of diesel versus gasoline powerplants for specific makes and models of passenger cars over the period 1979-1983 (Greene, 1986). Estimated price slopes ranged from -0.00029 (for Mercedes) to -0.00205 (Buick). The average price of a passenger car in 1983 was $\$ 10,640$ (1993\$; MVMA, 1989, p. 40). Assuming a car price of $\$ 10,000$, a price slope of -0.002 gives an elasticity of -10 . A price slope of -0.0003 and price of $\$ 30,000$ implies and elasticity of -4 at a $50 \%$ share. These price elasticity estimates are considerably higher than those for choices across all types of vehicles. A survey of a dozen such models chose -0.00056 as a typical price slope, which given a $\$ 10,000$ vehicle price and a $50 \%$ share results in a price elasticity of -2.8 . The pioneering estimation of a MNL model of vehicle type choice by Lave and Train (1979) produced a typical price slope of -0.00066 , implying a price elasticity of -3 at $50 \%$ market share.

The price elasticity of fuel type choice for multi-fuel vehicles should be lower than that for choice of grade of gasoline ( -40 to -20$)$ but two to three times higher than for choice of alternative fuel vehicle. The price elasticity of AFV choice should be similar to that found by Greene (1986) for diesel engine choice (about -5 to -10 ), and higher than that in studies that consider choices across all vehicle types (about -3 ). Based on the available empirical studies, a range of elasticities of -20 to -10 for fuel choice and -5 to -10 for vehicle choice appears to be reasonable, although higher elasticities might be justifiable.

For each multi-fuel vehicle type (i), a fuel price elasticity $\left(\beta_{i}\right)$ at a specified market share $\left(s_{i}=50 \%\right)$ is assumed. Given an initial gasoline price, the fuel price slope $\left(b_{i}\right)$ is computed using the price of gasoline, $\boldsymbol{\beta}_{\mathrm{i}}$, and $\mathrm{s}_{\mathrm{i}}$.

$$
b_{i}=\frac{\beta_{g}}{P_{g}\left(1-s_{g}\right)}
$$

In the absence of information to the contrary, we assume the same elasticity for all multi-fuel vehicle types although this assumption can be easily changed. The values of non-price fuel-specific attributes $\left(\mathrm{V}_{\mathrm{ij}}\right)$ are then summed to obtain an overall hedonic value per gallon of gasoline equivalent. This is converted to barrels by multiplying by 42 . The hedonic value in dollars is converted to a fuel-specific logit coefficient, $A_{i j}$, by multiplying by the respective fuel price slope, $b_{i}$. 


\subsubsection{Estimation of Inclusive Values for Multi-Fuel and Single-Fuel Vehicles}

In a random utility model such as the NMNL, an option does not have a fixed value but rather a probability distribution of values. As a result, the value of a nested set of options cannot be described simply by the average of the values of its components or even by the value of its most desirable option..$^{22}$ Instead, the ability to choose the highest value option from among those in the nested set gives the set a higher expected value than that of any single choice in the set. The expected cost of a nested choice set is given by equation (2.9) in Section 2, above.

The inclusive value, or expected generalized cost of a nest is passed directly to the respective vehicle choice equation, where it is added to the generalized cost of the vehicle-specific characteristics (see eq. 2.10) and multiplied by the vehicle price coefficient, $\beta$, to yield the generalized cost for the vehicle type (i). For single-fuel vehicles the inclusive value term collapses to the generalized cost of the fuel-specific characteristics for that vehicle type, $c_{i j}=c_{i}$.

Multi-Fuel: $\quad C_{i}=\beta\left(u_{i}+\overline{c_{j}}\right) \quad$ Single-Fuel: $\quad C_{i}=\beta\left(u_{i}+c_{i j}\right)$

Vehicle shares may then be computed using equation (2.10).

\footnotetext{
${ }^{22}$ In the case where the generalized cost coefficient is very large, the value of the nested choice set will approach the expected value of the single option with the greatest expected value.
} 


\section{IMPLEMENTATION OF THE ALTERNATIVE FUEL VEHICLE CHOICE MODEL AS A SPREADSHEET}

The Alternative Fuel and Vehicle Choice (AFVC) Model has been implemented in the form of a computer model using the Excel spreadsheet software. Seven spreadsheets combined as an Excel Workbook comprise the model. The individual worksheets are:

1. AFTM and AFVC Scenario,

2. Calculation of Value of Range and Refueling Time,

3. Calculation of Performance Values,

4. Calculation of Value of Lost Cargo Space,

5. Calculation of Fuel Choice Option Values,

6. Calculation of AFVC Model Parameters for AFTM, and

7. Macro Spreadsheet to Control Printing and Recalculation.

This section describes each spreadsheet and its operation. The sole function of the Macro spreadsheet (7) is to print each of the other six thereby documenting a particular model run. Details of this spreadsheet will therefore not be described here.

\subsection{AFTM FUEL AND VEHICLE CHOICE SCENARIO}

The "Scenario" spreadsheet contains the key assumptions used in the other spreadsheets to value AFV attributes and calculate logit coefficients. Five categories of data are included:

1. AFV characteristics,

2. vehicle economics,

3. vehicle attribute (hedonic) values,

4. fuel prices, and

5. choice elasticity assumptions.

The "Scenario" spreadsheet serves as a convient, single table in which to enter all the critical numerical assumptions for the AFVC model (Figure 4.1). 
Figure 4.1 AFTM Fuel and Vehicle Choice Scenario

Fuel Prices (\$/bbl GE)

Gasoline $\$ 55.02$

Reformulated Gaso. $\$ \mathbf{\$ 8 . 6 0}$

M85 \$55.86

E85 $\$ 75.18$

CNG $\$ 55.02$

LPG $\$ 49.56$

Electric $\$ 107.93$

Hedonic Values

Value of cubic foot of cargo spece

Value of $1 \%$ change in H.P.MM ratio

Value of hour to refuel (non-electric)

value of hour to refuel electric vehicles

Elastlcity Specilications

Vehicle: base share

Vehicle: elasticity

Fuel: base share

Fuel: elesticity

\begin{tabular}{cr}
\multicolumn{2}{c}{ Yehlcle Economics } \\
\cline { 2 - 2 } Armual Miles & 11,383 \\
Average MPG & 21.30 \\
Discount rate & $7.0 \%$ \\
Depreciation rete & $15.0 \%$ \\
Years of ownership & 4 \\
Capital recovery factor & 0.168 \\
Base Vehicle Price & $\$ 16,700$
\end{tabular}

$\$ 25.00$

$\$ 25.00$

$\$ 10.00$

$\$ 1.00$

$\begin{array}{ccrr}50 \% & & & \\ -10.00 & & & \\ \text { Flox-Fuat Veh. } & \text { CNG Bifuel LPG Bifuel } & \text { Alochol Ded. } \\ 50 \% & 50 \% & 50 \% & 50 \% \\ -20.00 & -20.00 & -20.00 & -20.00\end{array}$

\begin{tabular}{|c|c|c|c|c|c|c|c|c|c|}
\hline Vehiche & Euel & $\begin{array}{l}\text { Relative } \\
\text { Enorgy } \\
\text { Efficiency }\end{array}$ & $\begin{array}{l}\text { Change } \\
\text { In Vehicte } \\
\text { Weight }\end{array}$ & $\begin{array}{l}\text { Change } \\
\text { in H.P. }\end{array}$ & $\begin{array}{l}\text { Storage } \\
\text { Spece } \\
\text { (gallons) }\end{array}$ & $\begin{array}{c}\text { Storage } \\
\text { in Units } \\
\text { (agl. sct.kWh }\end{array}$ & $\begin{array}{c}\text { Refueling } \\
\text { Time } \\
\text { (minutes) }\end{array}$ & $\begin{array}{c}\text { Search } \\
\text { Time } \\
\text { (minutes) }\end{array}$ & $\begin{array}{l}\text { Additional } \\
\text { Vehich Coot } \\
\text { (SNehicle) }\end{array}$ \\
\hline Conventional & Gasoline & $100.0 \%$ & $0.00 \%$ & $0.00 \%$ & 15.8 & 15.4 & 6.0 & 0.0 & $\$ 0$ \\
\hline $\begin{array}{l}\text { Flex-Fuel Veh. } \\
\text { Flex-Fuel Veh. } \\
\text { Flex-Fuel Veh. }\end{array}$ & $\begin{array}{c}\text { Gasoline } \\
\text { M85 } \\
\text { E85 }\end{array}$ & $\begin{array}{l}100.0 \% \\
101.0 \% \\
101.0 \%\end{array}$ & $0.00 \%$ & $\begin{array}{l}0.00 \% \\
3.00 \% \\
3.00 \%\end{array}$ & 18.5 & $\begin{array}{l}18.0 \\
18.0 \\
18.0\end{array}$ & $\begin{array}{l}6.0 \\
6.0 \\
6.0\end{array}$ & $\begin{array}{l}0.0 \\
0.0 \\
0.0\end{array}$ & $\$ 100$ \\
\hline $\begin{array}{l}\text { CNG Bifuel } \\
\text { CNG Bifuel }\end{array}$ & $\begin{array}{l}\text { Gasoline } \\
\text { CNG }\end{array}$ & $\begin{array}{l}97.0 \% \\
97.0 \%\end{array}$ & $4.70 \%$ & $\begin{array}{r}0.00 \% \\
-10.00 \%\end{array}$ & 51.8 & $\begin{array}{r}15.4 \\
650.0\end{array}$ & $\begin{array}{l}6.0 \\
7.5\end{array}$ & $\begin{array}{l}0.0 \\
0.0\end{array}$ & $\$ 817$ \\
\hline $\begin{array}{l}\text { LPG Bifuel } \\
\text { LPG Bifuel }\end{array}$ & $\begin{array}{l}\text { Gasoline } \\
\text { LPG }\end{array}$ & $\begin{array}{l}98.0 \% \\
98.0 \%\end{array}$ & $3.70 \%$ & $\begin{array}{l}0.00 \% \\
-5.00 \%\end{array}$ & 37.0 & $\begin{array}{l}15.4 \\
20.0\end{array}$ & $\begin{array}{l}6.0 \\
6.5\end{array}$ & $\begin{array}{l}0.0 \\
0.0\end{array}$ & $\$ 625$ \\
\hline $\begin{array}{l}\text { CNG Dedicated } \\
\text { LPG Dedicated }\end{array}$ & $\begin{array}{l}\text { CNG } \\
\text { LPG } \\
\end{array}$ & $\begin{array}{l}100.0 \% \\
100.0 \% \\
\end{array}$ & $\begin{array}{l}6.50 \% \\
2.00 \% \\
\end{array}$ & $\begin{array}{l}0.00 \% \\
0.00 \% \\
\end{array}$ & $\begin{array}{l}49.9 \\
21.2 \\
\end{array}$ & $\begin{array}{r}1300.0 \\
20.0 \\
\end{array}$ & $\begin{array}{l}8.0 \\
6.5 \\
\end{array}$ & $\begin{array}{l}0.0 \\
0.0 \\
\end{array}$ & $\begin{array}{l}\$ 451 \\
\$ 171\end{array}$ \\
\hline $\begin{array}{l}\text { Alcohol Ded. } \\
\text { Alcohol Ded. }\end{array}$ & $\begin{array}{l}\text { M85 } \\
\text { E85 }\end{array}$ & $\begin{array}{l}105.0 \% \\
105.0 \% \\
\end{array}$ & $0.00 \%$ & $\begin{array}{l}10.00 \% \\
10.00 \%\end{array}$ & $\begin{array}{l}18.5 \\
18.5 \\
x\end{array}$ & $\begin{array}{l}18.0 \\
18.0\end{array}$ & $\begin{array}{l}6.5 \\
6.5\end{array}$ & $\begin{array}{l}0.0 \\
0.0\end{array}$ & 50 \\
\hline Eloctric & 3attery EV & $429.4 \%$ & & 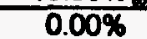 & & & & & \\
\hline
\end{tabular}


Nine characteristics must be entered for each AFV:

1. Relative efficiency (per gallon of gasoline energy equivalent)

2. Change in vehicle weight (versus $\mathrm{CV}$ )

3. Change in horsepower

4. Fuel storage volume

5. Quantity of fuel stored (in customary units, not used)

6. Refueling time

7. Fuel search time (not used)

8. Additional vehicle cost

Relative efficiency is specified as a percent of conventional gasoline vehicle and assumes that efficiency for all vehicle types has been measured on the basis of energy equivalent to one gallon of gasoline. Change in weight is the percent increase or decrease versus a conventional vehicle, and change in horsepower is similarly measured. Storage space must be given in gallons, and must represent the total volume required by the fuel storage system which is slightly greater than the volume of fuel stored. Storage in units is the quantity of fuel stored, given in customary units: gallons for liquids, standard cubic feet (SCF) for gases, and kilowatt hours (kWh) for electricity. Refueling time is given in minutes and represents only the time spent refueling, not the time spent traveling to or searching for a refueling station. Again, it is assumed that multifuel vehicles must be refueled one fuel at a time. Search time has been included for possible future use but does not enter into any current AFTM scenarios. Additional vehicle cost is the incremental purchase cost of the AFV to the consumer. Note that changes in weight, storage space, and additional cost are vehicle-, but not fuel-specific. All other variables are vehicle- and fuel-specific.

Vehicle economic factors include average annual miles per vehicle, average miles per gallon, and average sales price of a new gasoline vehicle. Three additional variables must be supplied to compute the capital recovery factor: (1) the annual real discount rate, (2) the annual capital depreciation rate for light duty vehicles, and (3) the estimated term of ownership for new car buyers, in years.

Hedonic values, dollar values per unit of vehicle characteristic or per time, must also be specified in the "Scenario" spreadsheet. The tow hedonic parameters required are the value of one cubic foot of cargo space and the value of a $1 \%$ change in the ratio of horsepower to vehicle weight, a measure of performance. Two values of time must be entered, one for refueling all but electric vehicles (EVs), the other for the time required to recharge EVs. 
Price elasticities must be provided for the vehicle and fuel choice equations. Elasticities are unitless, representing the ratio of relative (\%) change in market share corresponding to a relative (\%) change in price. As noted above in the theoretical discussion of the AFVC model, the elasticity of fuel type choice must be greater in absolute value than that of vehicle type choice. In addition to a base price and elasticity, the market share at which the elasticity applies is required.

Finally, price estimates per barrel of gasoline equivalent must be supplied for each fuel. These prices are used in the estimation of the value of the fuel choice option for multi-fuel vehicles. They should therefore be as close as practical to the final AFTM equilibrium prices for the scenario in question. This should require only one iteration to achieve reasonable convergence (producing a set of AFVC coefficients, entering them in the AFTM, running it and reentering the resulting prices in the AFVC spreadsheet).

\subsection{CALCULATION OF VALUE OF RANGE AND REFUELING TIME}

This spreadsheet estimates the cost of additional time spent refueling alternative fuel vehicles. The total change in refueling time is comprised of two components: (1) more frequent refueling (range), and (2) greater time required per refueling. The two are computed in terms of dollars per barrel of gasoline equivalent and added to produce the range and refueling time cost.

The "Refueling" spreadsheet carries forward average annual miles traveled and average miles per gallon from the "Scenario" spreadsheet. In addition, it brings forward: (1) fuel storage capacity, in customary units; (2) relative fuel efficiency; (3) station time per refueling event; and (4) the value of time spent refueling. The energy content of a customary unit of fuel must be specified by the user in this spreadsheet (Figure 4.2).

The first step is calculation of the range per refill for each fuel type. This is by definition either the (1) range on a full tank, minus a ninety mile reserve for liquid fuels, (2) ninety-five percent of the full range for bi-fuel gaseous fuels, or (3) seventy-five percent of the maximum range for batteryelectric vehicles. First, storage in customary units is converted to storage in million Btu by multiplying tank size, $Q_{i}$, by energy content $B_{i}$. Relative efficiency, $R_{i}$, which is the ratio of AFV miles per gallon of gasoline equivalent energy to CV MPG, is multiplied by the ratio of AFV to CV energy storage capacity, and the product is multiplied by $\mathrm{CV}$ range to obtain the range for a "full tank," $\mathrm{M}_{\mathrm{i}}$. 


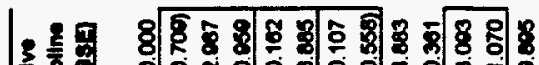

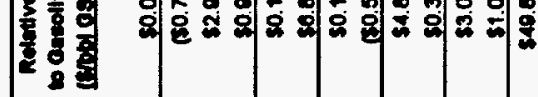

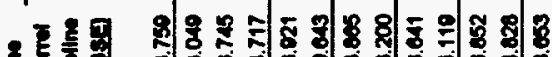

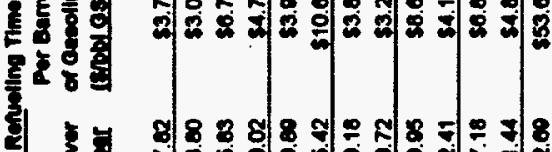
홍 $>\quad 88888888888$ 章年

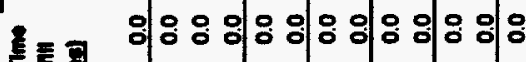

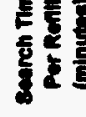

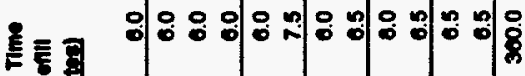
案家

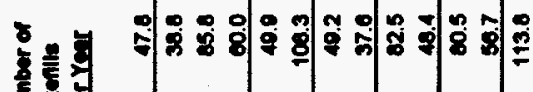

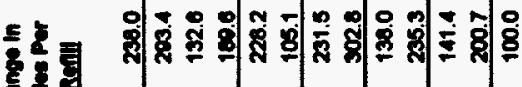

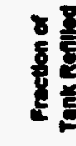

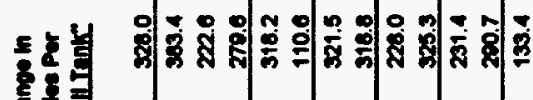

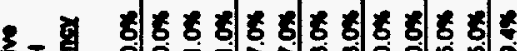

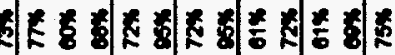

赵离

与융

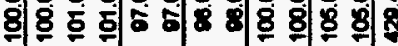

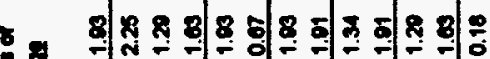

量崀

$-000.0 .000$

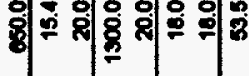

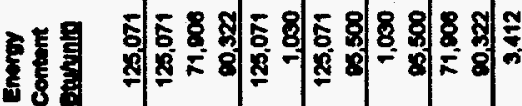

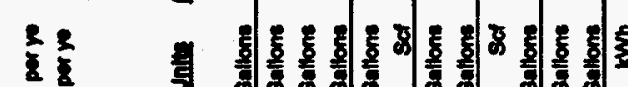

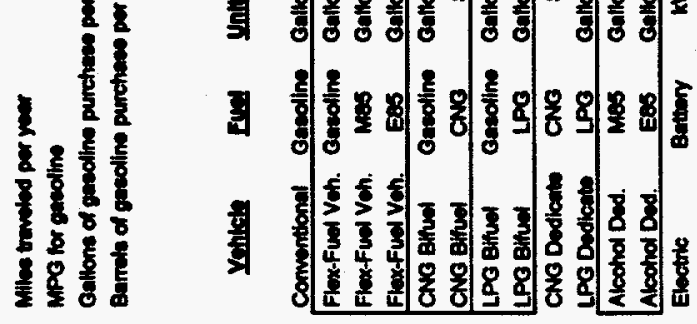

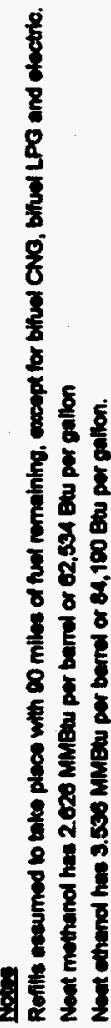




$$
M_{i}=\frac{B_{i} Q_{i}}{B_{g} Q_{g}} R_{i} \cdot M_{g}=\frac{B_{i} Q_{i}}{B_{g} Q_{g}} \cdot \frac{(M P G)_{i}}{(M P G)_{g}} \cdot M_{g}
$$

Range per refill $\left(\mathrm{M}_{\mathrm{i}}\right)$ is simply $\mathrm{M}_{\mathrm{i}}-90$ for liquid fuels, $0.95 \mathrm{M}_{\mathrm{i}}$ for gaseous bi-fuel vehicles, and $0.75 \mathrm{M}_{\mathrm{i}}$ for EVs.

The cost per barrel of gasoline equivalent energy is computed as follows. Average annual miles, $\mathrm{A}$, is divided by range per refill to obtain the average number of refills per year. This is multiplied by the estimated station time (converted to hours) required per refill (plus the search time which is assumed to be zero in all cases), times the average value of time, $\mathrm{W}$, to obtain the total annual time cost of refueling, $T_{i}$.

$$
T_{i}=\frac{A}{m_{i}} \cdot\left(t_{i} / 60\right) \cdot W
$$

The annual refueling time cost is $\mathrm{T}_{\mathrm{i}}$, divided by the annual fuel consumption in barrels of gasoline to obtain refueling time cost per barrel of gasoline energy service equivalent. The incremental refueling cost per barrel is simply the AF refueling cost per barrel minus the gasoline refueling cost.

$$
\Delta t_{i}=\frac{t_{i}}{G}-\frac{t_{g}}{G}=\frac{t_{i}-t_{g}}{G}
$$

\subsection{CALCULATION OF LOST CARGO SPACE VALUE}

In general, alternative fuel vehicles will require more volume for energy storage than a conventional gasoline-powered vehicle. In this spreadsheet, assumptions about the on-board storage requirements of AFVs are translated into an equivalent loss of cargo space and the lost cargo space is translated into a dollar charge per barrel of gasoline equivalent energy service.

Four data are passed from the "Scenario" spreadsheet to the "Cargo" spreadsheet (Figure 4.3):

1. the average dollar value of 1 cubic foot of cargo space (C),

2. the annual capital recovery factor $(R)$, 
Figure 4.3 Calculation of Value of Lost Cargo Space

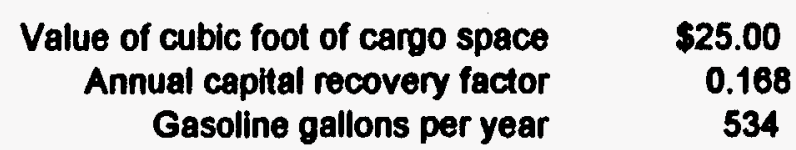

\begin{tabular}{|c|c|c|c|c|c|c|c|}
\hline \multirow[b]{3}{*}{ Vehicle } & \multirow[b]{3}{*}{ Fuel } & \multicolumn{3}{|c|}{ Fuel Storage Space } & \multirow{2}{*}{\multicolumn{3}{|c|}{ Cost (Benefit) of Change }} \\
\hline & & \multirow[b]{2}{*}{ In Gallons } & \multirow{2}{*}{$\begin{array}{l}\text { Relative } \\
\text { to Gasoline } \\
\text { in Gallons }\end{array}$} & \multirow{2}{*}{$\begin{array}{c}\text { Relative } \\
\text { to Gasoline } \\
\text { in CuFt }\end{array}$} & & & \\
\hline & & & & & $\begin{array}{c}\text { Value of a } \\
\text { New Vehicle }\end{array}$ & (\$/gal.GSE) & (S/bbl. GSE) \\
\hline Conventional & Gasoline & 15.8 & 0.0 & 0.0 & $\$ 0$ & $\$ 0.000$ & $\$ 0.000$ \\
\hline FFV & Gasoline & 18.5 & 2.7 & 0.4 & $\$ 9$ & $\$ 0.003$ & $\$ 0.120$ \\
\hline FFV & M85 & 18.5 & 2.7 & 0.4 & $\$ 9$ & $\$ 0.003$ & $\$ 0.120$ \\
\hline FFV & E85 & 18.5 & 2.7 & 0.4 & $\$ 9$ & $\$ 0.003$ & $\$ 0.120$ \\
\hline CNG Bifuel & Gasoline & 51.8 & 36.0 & 4.9 & $\$ 122$ & $\$ 0.038$ & $\$ 1.603$ \\
\hline CNG Bifuel & CNG & 51.8 & 36.0 & 4.9 & $\$ 122$ & $\$ 0.038$ & $\$ 1.603$ \\
\hline LPG Bifuel & Gasoline & 37.0 & 21.2 & 2.9 & $\$ 72$ & $\$ 0.022$ & $\$ 0.944$ \\
\hline LPG Bifuel & LPG & 37.0 & 21.2 & 2.9 & $\$ 72$ & $\$ 0.022$ & $\$ 0.944$ \\
\hline CNG Dedicated & CNG & 49.9 & 34.1 & 4.6 & $\$ 115$ & $\$ 0.036$ & $\$ 1.519$ \\
\hline LPG Dedicated & LPG & 21.2 & 5.4 & 0.7 & $\$ 18$ & $\$ 0.006$ & $\$ 0.240$ \\
\hline AFV & M85 & 18.5 & 2.7 & 0.4 & $\$ 9$ & $\$ 0.003$ & $\$ 0.120$ \\
\hline AFV & E85 & 18.5 & 2.7 & 0.4 & $\$ 9$ & $\$ 0.003$ & $\$ 0.120$ \\
\hline Electric & Battery EV & 38.7 & 22.9 & $\overline{3.1}$ & $\$ 77$ & $\$ 0.024$ & $\$ 1.020$ \\
\hline
\end{tabular}

Notes:

Each gallon represents 7.4 cubic feet of space. 
3. the average annual gasoline consumption (G), and

4. fuel storage volumes, in gallons $\left(V_{i}\right)$.

The value of cargo space lost to fuel storage is computed as follows. First the fuel storage volume required for gasoline is subtracted from the alternative fuel storage volume $V_{i}$ to obtain an estimate of gallons of cargo space lost. ${ }^{23}$ Gallons are converted to cubic feet by dividing by 7.4. Cubic feet of cargo space lost is multiplied by the assumed dollar value per cubic foot, $\mathrm{C}$, to obtain the present value (or vehicle price-equivalent value) of lost cargo space. This is converted to a capital charge per barrel by multiplying by the capital charge rate, dividing by the average annual fuel consumption in gallons, and multiplying by the number of gallons per barrel (42). The complete equation for the value of lost cargo space per barrel of gasoline equivalent energy service is,

$$
\left.\left.P_{\text {cargo }}=\left(V_{i}-V_{G}\right) / 7.4\right] C \cdot R / G\right) 42
$$

\subsection{CALCULATION OF PERFORMANCE VALUE}

In this spreadsheet, changes in performance (expressed as percent changes in the ratio of horsepower to weight) are translated into dollar charges per barrel of gasoline equivalent energy service. Although some causes of performance changes, such as the additional weight of storage tanks on a bi-fuel vehicle, are inherent to the vehicle regardless of the fuel used, all performance changes are treated as fuel-specific. It is a characteristic of the nested MNL model that costs that are common to all the fuels that an AFV can use will not affect the choice of fuel for that vehicle type but will affect the decision to choose that vehicle type. This can be seen from the definition of average general cost, $\bar{c}_{i}$, in equation (9) above. If we assume that a component, $\mathrm{K}_{\mathrm{i}}$, of the costs of fuels for vehicle type $i$ are common to the vehicle and do not vary over fuel type (j), we can write the average generalized fuel cost as,

\footnotetext{
${ }^{23}$ In general, the total volume required for a fuel storage system will be somewhat greater than the volume of fuel stored.
} 


$$
\begin{gathered}
\bar{c}_{i}=\frac{l}{\mu_{i}} \ln \sum_{j=i}^{N_{i}} e^{\mu_{i} C_{i} \cdot \mu_{i} K_{i}}=\frac{1}{\mu_{i}} \ln e^{\mu_{i} K_{i}} \sum_{j=i}^{N_{i}} e^{\mu_{i} C_{i j}} \\
=K_{i}+\frac{l}{\mu_{i}} \ln \sum_{j=i} e^{\mu_{i} c_{i j}}
\end{gathered}
$$

Thus the common cost component, $\mathrm{K}_{\mathrm{i}}$, carries through to the vehicle choice equation but will "cancel out" of the fuel choice equation. Thus, we can treat all performance costs as if they were fuel costs without affecting the AFVC model at all.

The "Performance" spreadsheet obtains several data items from the "Scenario" spreadsheet (Figure 4.4):

1. the value of a $1 \%$ change in H.P./weight,

2. the annual capital recovery factor,

3. the average annual gasoline service equivalent consumption, in gallons,

4. the \% change in vehicle weight, and

5 . the $\%$ change in horsepower by vehicle and fuel type.

The $\%$ change in H.P./wt., $\Delta \mathrm{h}$, is computed from the $\%$ change in horsepower, $\Delta \mathrm{H}$, and weight, $\Delta W$, as follows,

$$
\Delta h_{i}=\frac{1+\Delta H_{i}}{1+\Delta W_{i}}-1
$$

Note that the variables are actually fractional rather than percent changes although they are displayed in the spreadsheet in \% format.

The values of the $\Delta h_{i}$ are computed by multiplying times the value of a $1 \%$ change in H.P./wt. and again times 100 . This gives the value in vehicle purchase price equivalent dollars. This is divided by average annual consumption, in gallons, and multiplied by 42 to derive the cost per barrel of gasoline equivalent energy service. 
Figure 4.4 Calculation of Performance Values

Value of $1 \%$ change in H.P.Mt Annual capital recovery factor

Gasoline gallons per year
$\$ 25.00$
0.168
534

Cost (Benefit) of Change

Change in Change Change in Value of a Vehicle Weight in H.P. H.P.WH Ratio New Vehicle (\$/gal.GSE) 1 \$/bbl.GSE)

\begin{tabular}{|c|c|c|c|c|c|c|c|}
\hline Vehicle & Fuel & Vehicle Weight & in H.P. & H.P.Mt Ratio & New Vehicle & (\$/gal. GSE) & (S/bbl. GSE) \\
\hline Conventional & Gasoline & $0.00 \%$ & $0.00 \%$ & $0.00 \%$ & $\$ 0$ & $\$ 0.000$ & $\$ 0.000$ \\
\hline $\mathrm{FV}$ & Gasoline & $0.00 \%$ & $0.00 \%$ & $0.00 \%$ & $\$ 0$ & $\$ 0.000$ & $\$ 0.000$ \\
\hline$V$ & M85 & $0.00 \%$ & $3.00 \%$ & $3.00 \%$ & $(\$ 75)$ & $(\$ 0.024)$ & $(\$ 0.889)$ \\
\hline FV & E85 & $0.00 \%$ & $3.00 \%$ & $3.00 \%$ & (\$75) & $(\$ 0.024)$ & $(\$ 0.989)$ \\
\hline NG Bifuel & Gasoline & $4.70 \%$ & $0.00 \%$ & $-4.49 \%$ & $\$ 112$ & $\$ 0.035$ & $\$ 1.479$ \\
\hline NG Bifuel & CNG & $4.70 \%$ & $-10.00 \%$ & $-14.04 \%$ & $\$ 351$ & $\$ 0.110$ & $\$ 4.627$ \\
\hline PG Bifuel & Gasoline & $3.70 \%$ & $0.00 \%$ & $-3.57 \%$ & $\$ 89$ & $\$ 0.028$ & $\$ 1.176$ \\
\hline PG Bifuel & LPG & $3.70 \%$ & $-5.00 \%$ & $-8.39 \%$ & $\$ 210$ & $\$ 0.066$ & $\$ 2.765$ \\
\hline NG Dedicated & CNG & $6.50 \%$ & $0.00 \%$ & $-6.10 \%$ & $\$ 153$ & $\$ 0.048$ & $\$ 2.011$ \\
\hline PG Dedicated & LPG & $2.00 \%$ & $0.00 \%$ & $-1.96 \%$ & $\$ 49$ & $\$ 0.015$ & $\$ 0.646$ \\
\hline$F V$ & M85 & $0.00 \%$ & $10.00 \%$ & $10.00 \%$ & $(\$ 250)$ & $(\$ 0.078)$ & $(\$ 3.296)$ \\
\hline$F V$ & E85 & $0.00 \%$ & $10.00 \%$ & $10.00 \%$ & $(\$ 250)$ & $(\$ 0.078)$ & $(\$ 3.296)$ \\
\hline
\end{tabular}




\subsection{ALTERNATIVE FUELS OPTION VALUE CALCULATION}

This spreadsheet estimates the expected value of the option an AFV owner has of buying the cheapest fuel as fuel prices fluctuate over time. It is this spreadsheet that requires a set of prices for all fuels that is reasonably close to the final solution set produced by a given AFTM scenario. The "Option" spreadsheet uses the prices per barrel of gasoline equivalent energy service entered in the "Scenario" spreadsheet. It also checks the "Shares" spreadsheet to see if the type of conventional gasoline assumed is reformulated, or not. Finally, the user is required to enter the parameters of a bivariate normal distribution of prices for two hypothetical fuels:

1. mean fuel prices for the two fuels (values entered do not affect the calculation of option values),

2. standard deviations of fuel prices as a fraction the respective mean (these do matter), and

3. the correlation coefficient for fuel prices (this also matters).

Using the bivariate normal distribution parameters the spreadsheet completes three tables:

1. bivariate normal probability densities,

2. the table of expected savings on fuel 1 , and

3. the table of expected savings on fuel 2.

The expected savings in the two tables are summed, added to the difference of mean prices, and the total is divided by two to obtain the option value [according to equation (3.8) above]. Since this value is in gallons, it is multiplied by 42 to give the per barrel value.

A "what-if" table is used to compute option values for each relevant pair of fuels. The actual per barrel prices form the margins of the table and are correspondingly used as the mean prices for computing option values. This is why the mean prices initially entered do not matter, they are simply placeholders for the actual fuel price pairs. Unless the prices used in the "what-if" table are reasonably close to the final AFTM equilibrium prices, the estimated option values will not be accurate. Experience shows, however, that a single iteration is sufficient to achieve pennies per barrel accuracy because option values do not greatly influence market equilibrium prices. Thus, one may run a new AFTM scenario with MNL coefficients computed without option values or with option values computed with a previous scenario's prices, obtain a new set of market prices, substitute these into the AFVC "Scenario" spreadsheet, recompute MNL coefficients and then 
complete the final AFTM run with the second generation coefficients. No further iteration is likely to be necessary to achieve price convergence of $1-2$ cents per barrel.

\subsection{VEHICLE AND FUEL CHOICE MARKET SHARES CALCULATION}

This final spreadsheet in the workbook calculates the AFVC choice model parameters and produces preliminary estimates of market shares (Figure 4.5). Only the model coefficients are passed to the AFTM; the shares estimates are computed for the purpose of checking for errors and for sensitivity analyses of key parameters. The only new item of data entered in the "Shares" spreadsheet is a designation of whether reformulated or conventional gasoline is the default fuel.

First the generalized cost coefficients $\left(\beta, \mu_{\mathrm{i}}\right)$ are computed using information contained in the "Scenario" spreadsheet. The vehicle choice coefficient is calculated by dividing the price elasticity by the product of the base price and 1 minus the corresponding market share. Base price is expressed in dollars per barrel of gasoline equivalent energy service and comprises vehicle purchase cost, fuel cost, and hedonic costs. The elasticity must therefore be the market share elasticity of generalized cost rather than the elasticity of vehicle purchase cost. The generalized cost elasticity will always be greater (in absolute value) than the purchase price elasticity in proportion to the ratio of generalized cost to vehicle price (see equation 4.2 below). Here, generalized cost exceeds vehicle purchase price by about $25 \%$. Thus if the vehicle price elasticity were -8 , the generalized cost elasticity would be about -10 . The generalized cost coefficient for fuel shares $\left(\mu_{\mathrm{i}}\right)$ is directly computed by dividing the specified elasticity by the gasoline service equivalent fuel price times 1 minus the corresponding market share. In this version of the spreadsheet only a single, common $\mu$ is computed, although it is not necessary in theory that $\mu_{\mathrm{i}}=$ $\mu$ for all $i$ multifuel vehicle types. A single $\mu$ is used here due to the lack of information about how elasticity may vary by type of AFV.

The remainder of the spreadsheet consists of two tables. In the larger table, fuel prices and hedonic values from the other spreadsheets are displayed and used to compute, (1) MNL model intercept terms for fuels and vehicles, and (2) preliminary market shares for fuels and vehicles. In the second table, fuel prices and hedonic values are displayed in terms of cents per mile. These are computed by dividing the hedonic costs in dollars per barrel of gasoline equivalent energy service by the average miles per barrel of gasoline. These data are provided solely as a more intuitive measure for checking the dollars per barrel estimates. 
Figure 4.5 AFTM Vehicle and Fuel Choice Market Shares

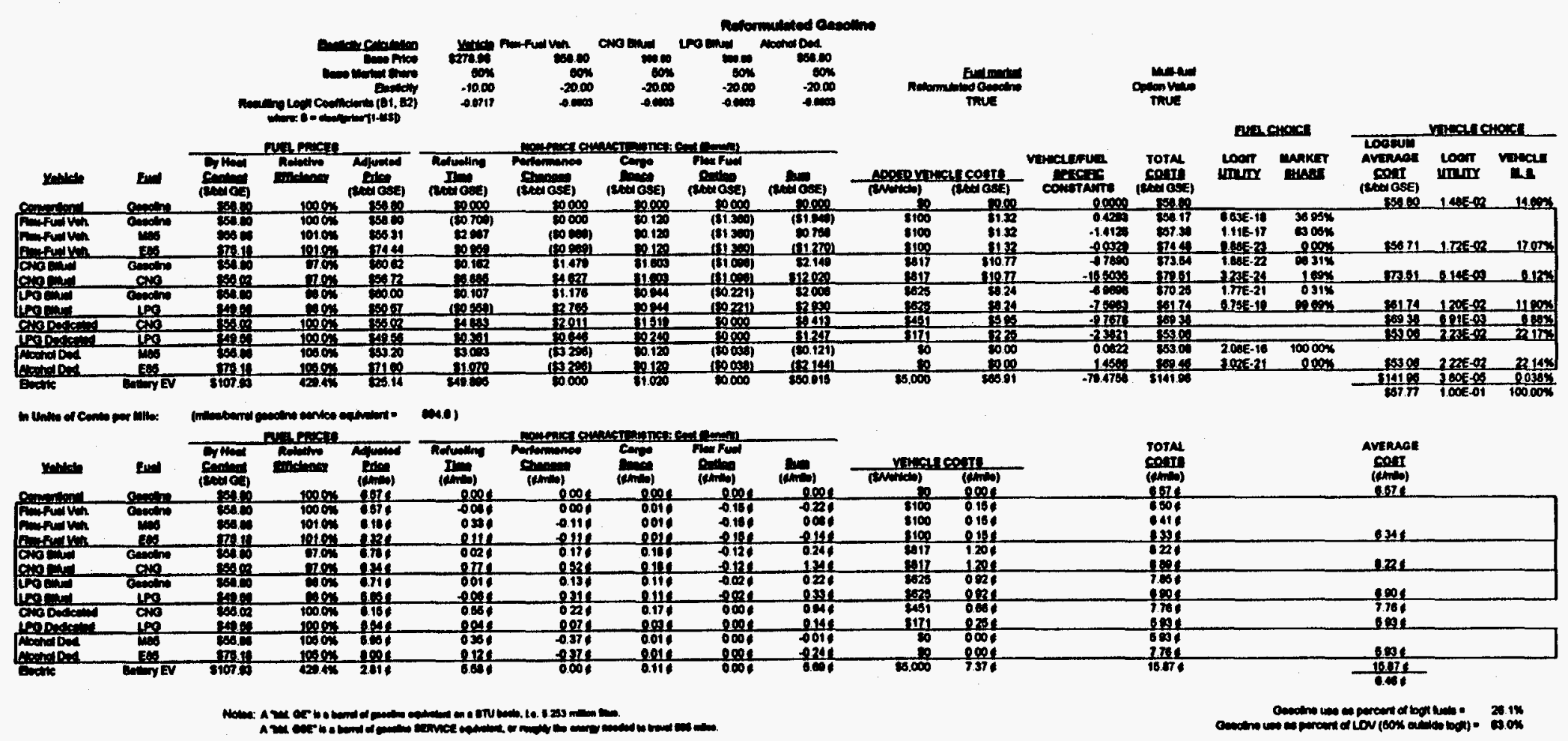


Calculation of MNL model constants and market shares begins by converting fuel prices in dollars per barrel of gasoline equivalent energy to dollars per barrel of gasoline equivalent energy service by dividing by relative fuel efficiency (this adjusted price is needed only for computing preliminary market shares). Next hedonic values for refueling time, performance, cargo space, and multi-fuel option value are extracted from their respective spreadsheets and summed to give total hedonic costs. Additional vehicle purchase cost is extracted from the "Scenario" spreadsheet and converted from capital cost to a charge per barrel of gasoline equivalent energy service in the usual way. These two are summed to give total non-fuel price costs. The sum is converted to a MNL fuel choice model constant by dividing by the relevant AFV generalized cost coefficient.

Note that since all vehicle-specific attributes as well as fuel- and vehicle-specific attributes have been included in the fuel- and vehicle-specific constants, there is no need for vehicle-specific constant terms. As we showed above in the section dealing with performance value, vehiclespecific constants will be simply passed through as costs from the fuel choice equation to the respective vehicle choice equation.

The computation of preliminary market shares continues with the calculation of total generalized cost as the sum of fuel and non-fuel costs. For multi-fuel vehicles this value is converted to utility by multiplying by the respective generalized cost coefficient, and then it is exponentiated.

$$
e^{U_{i j}}=e^{\mu_{i} C_{i j}}
$$

Market shares for fuel types are then directly computed by the logit equation

$$
S_{i j}=\frac{e^{v_{i j}}}{\sum_{j} e^{v_{i j}}}
$$

Vehicle type utilities are computed for dedicated AFVs by multiplying their total generalized cost times the vehicle choice generalized cost coefficient, $\beta$. For multi-fuel AFVs, utilities are computed by multiplying the generalized cost coefficient times the logarithm of the sum of the exponentiated utilities of their respective fuel types (the "logsum" term).

$$
U_{i}=\beta \frac{1}{\mu_{i}} \ln \left(\sum_{j=1}^{N_{i}} e^{\mu_{t} C_{c_{j}}}\right)
$$


Given all the $U_{i}$ for dedicated and multi-fuel AFVs, vehicle-type shares are computed by the logit equation.

$$
s_{i}=\frac{e^{U_{i}}}{\sum_{i} e^{U_{i}}}
$$




\section{SENSITIVITY OF AFVC MODEL TO KEY PARAMETERS}

The strategy used in developing the AFVC Model has been to construct a theoretical framework for integrating data and assumptions about alternative fuel vehicles and consumers' valuation of their attributes. One advantage of this approach is that it is amenable to sensitivity analysis. In this section we explore the sensitivity of the AFVC Model's predictions to assumptions about model parameters: 1) elasticities of vehicle and fuel choices to generalized cost, and 2) values attached to vehicle attributes and time spent refueling. This report does not explore the sensitivity of model predictions to vehicle characteristics. A common set of fuel prices representative of AFTM projections is assumed throughout, although sensitivity to fuel prices is also illustrated. In addition, a common set of assumptions about vehicle economics (use, MPG, cost, etc.) is also used (Table 5.1). In nearly all comparisons below, alternative fuels are compared to gasoline rather than reformulated gasoline. A comparison at the reformulated gasoline price is include to illustrate the price sensitivity of vehicle and market shares.

Table 5.1 Fuel Price and Vehicle Economics

\begin{tabular}{|l|r|l|r|}
\hline Fuel Prices (\$/bbl GE) & & Vehicle Economics & \\
\hline Gasoline & $\$ 55.02$ & Annual Miles & 11,383 \\
\hline Reformulated Gasoline & $\$ 58.80$ & Average MPG & 21.30 \\
\hline M85 & $\$ 55.86$ & Discount Rate & $7 \%$ \\
\hline E85 & $\$ 75.18$ & Depreciation Rate & $15 \%$ \\
\hline CNG & $\$ 55.02$ & Years of First Ownership & 4 \\
\hline LPG & $\$ 49.56$ & Capital Recovery Factor & 0.168 \\
\hline Electric & $\$ 107.93$ & Base Vehicle Price & $\$ 16,700$ \\
\hline
\end{tabular}

The key findings of this sensitivity analysis are: 1) that market shares of vehicles and fuels are reasonably stable given even large variations in assumptions about model parameters, 2) that lower elasticities of choice with respect to generalized cost produce a more even distribution of vehicle and fuel type shares, 3 ) the general pattern of market shares is not greatly affected by large variations in hedonic values, and 4) market shares depend strongly on fuel prices. These results 
suggest that model parameters would have to be radically different from those assumed in the base case to significantly alter the AFTM scenarios.

In the AFVC Model, elasticity determines the sensitivity of market shares to generalized costs. As pointed out above in the theoretical discussion of the nested multinomial logit model, sensitivity to cost is equivalent to the relative importance of unobserved attributes in the choice decision. Increasing the price elasticity makes market shares more sensitive to the costs of all factors, price and nonprice (hedonic). Thus, vehicle and fuels with a generalized cost advantage will get even larger market shares and those at a disadvantage will lose market share. Conversely, using lower price elasticities magnifies the importance of unobserved attributes, tending to distribute demand more equally across vehicle and fuel types.

The base case and alternative HIGH and LOW elasticity assumptions are shown in Table 5.2. All elasticity assumptions are made for a market share of $50 \%$ for ease of comparison. The base case assumes an elasticity of vehicle type choice of -10 , and fuel type choice elasticities twice as great, -20 . Because the full cost of a vehicle per barrel of gasoline equivalent energy service is about five time the cost of the fuel, the generalized cost parameter of the vehicle choice equation will be roughly one fifth as large at equal elasticities and one tenth as great at the elasticity values of the BASE case. The HIGH and LOW elasticity cases not only assume different elasticity values, but vary the fuel-type choice elasticities in a plausible way. The HIGH vehicle choice elasticity is 2.5 times the BASE case, the LOW is $30 \%$ of the BASE case value. In both the HIGH and LOW cases, the fuel choice elasticity for Bi-fuel CNG vehicles is half of the value for FFVs, that of Bi-Fuel LPG vehicles is three-fourths the FFV number, and the elasticity for Alcohol Flexible Vehicles is 1.5 times the FFV value.

Table 5.2 Alternative Elasticity Assumptions for Vehicle and Fuel Choices

\begin{tabular}{|c|r|r|r|r|r|}
\hline & $\begin{array}{l}\text { Vehicle } \\
\text { Choice }\end{array}$ & FFV & \multicolumn{1}{c|}{$\begin{array}{c}\text { Bi-Fuel } \\
\text { CNG }\end{array}$} & \multicolumn{1}{c|}{$\begin{array}{c}\text { Bi-Fuel } \\
\text { LPG }\end{array}$} & \multicolumn{1}{c|}{$\begin{array}{c}\text { Alcohol } \\
\text { FV }\end{array}$} \\
\hline BASE & -10 & -20 & -20 & -20 & -20 \\
\hline HIGH & -25 & -50 & -25 & -37.5 & -75 \\
\hline LOW & -3 & -10 & -5 & -7.5 & -15 \\
\hline
\end{tabular}

The effects of the three different elasticity assumptions on vehicle-type shares are illustrated in Figure 5.1. In the BASE case, Alcohol FV, LPG dedicated, and FFVs have nearly equal market 
shares at just over 19\%. Conventional gasoline vehicles are close behind at just over $17 \%$, followed by LPG bi-fuel (11\%), CNG dedicated and bi-fuel at about $6 \%$ each, and battery electric vehicles at 3 one-hundredths of a percent. Increasing the generalized cost elasticities boosts the Alcohol FV and FFV shares to $27 \%$ each or a combined total of about $55 \%$. Dedicated LPG and conventional gasoline vehicles also gain slightly to about $22 \%$ and $19 \%$, respectively. All remaining vehicle types account for under $5 \%$ of the total light duty vehicle market. Note that M85 is only slightly more expensive than gasoline, according to our price assumptions. At essentially equal price, M85 is an attractive fuel and vehicles that can use it are also attractive to consumers. FFVs cost little more than conventional vehicles and Alcohol FVs cost no more, according to our assumptions. With slightly improved performance and fuel economy counterbalancing slightly increased refueling costs, it should not be surprising that alcohol-capable vehicles garner a large share of the market. The relative success of dedicated LPG vehicles may seem surprising in light of the relatively small market share captured by other gaseous-fueled vehicles. According to our assumptions, however, dedicated LPG vehicle cost only about $\$ 200$ more than conventional gasoline vehicles, are closest to gasoline vehicles in range, and have equivalent performance and nearly equal fuel economy. On the plus side, LPG costs about $10 \%$ less than gasoline. It is also interesting to note that while most of the discussion about alternative fuel vehicles focusses on other fuels, LPG vehicles comprise $90 \%$ of the alternative fuel vehicles in use in the U.S. today (EIA, 1994, tables 3 and 4).

Figure 5.1 Vehicle Type Market Shares Sensitivity to Elasticity Assumptions
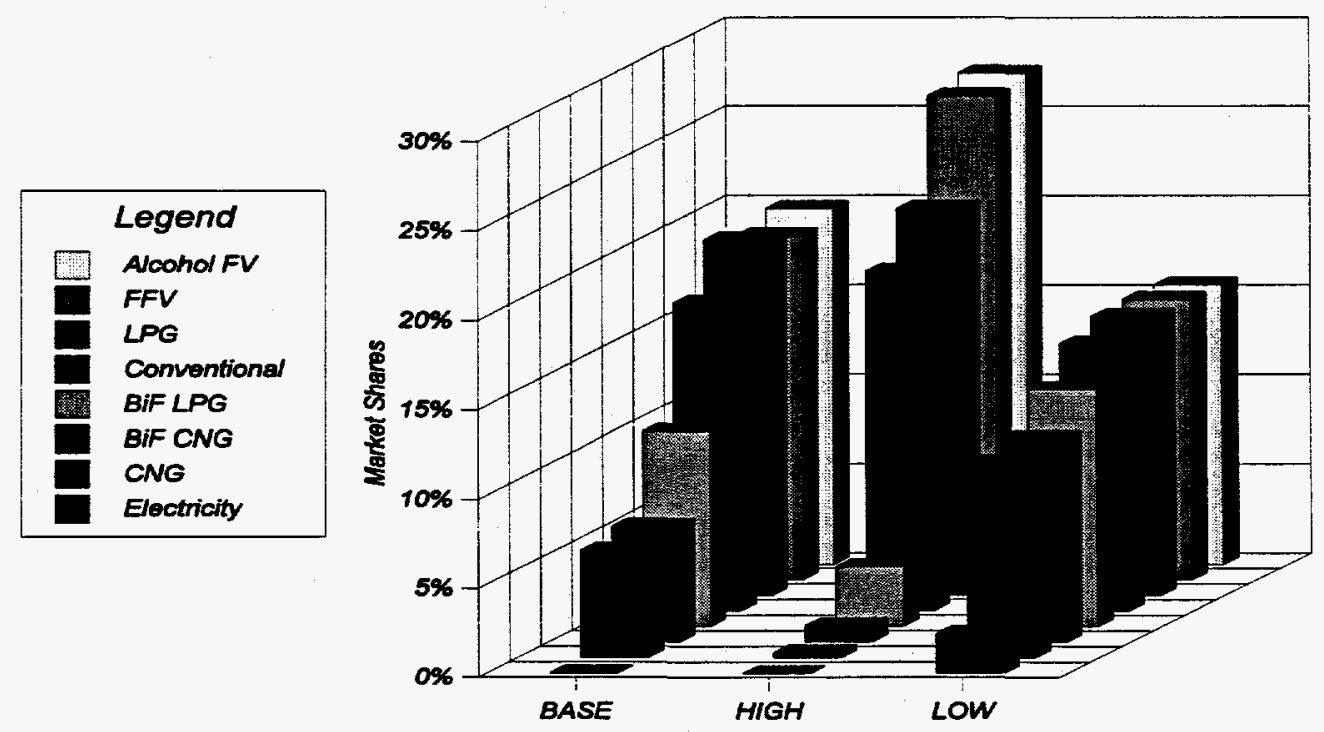
Lowering price elasticities tends to distribute sales more evenly across vehicle types. FFVs, Alcohol FVs, dedicated LPG, and conventional gasoline vehicles all get $15 \%$ market shares. This is closely followed by bi-fuel LPG (13\%), bi-fuel CNG (11\%) and dedicated CNG (11\%). Only battery electrics get a significantly smaller share $(2 \%)$. The tendency toward equal shares as elasticity decreases is a property of the multinomial logit model. Low elasticity implies reduced importance of generalized cost versus unobserved attributes. Since unobserved attributes are assumed to be equal across vehicle types, increasing their importance leads to a more equal distribution of market shares.

The alternative elasticity assumptions have a more pronounced effect on the market shares of fuels (Figure 5.2). Fuel shares were computed by multiplying fuel shares for multi-fuel vehicles by the vehicle type market share and adding up across vehicle types for each fuel type. Thus, the M85 share includes methanol fuel purchased for FFVs and Alcohol FVs. No attempt was made to attribute the gasoline component of alcohol fuels to gasoline, so that the actual amount of gasoline burned will be understated. In the BASE case, gasoline accounts for $42 \%$ of the fuel market, followed by LPG (30\%) and M85 (22\%). The reason for gasoline's larger share of the fuel market is that FFVs use gasoline nearly $90 \%$ of the time, and CNG Bi-Fuel vehicles use it almost all of the time. Although Alcohol FVs comprise 20\% of the market, E85 is essentially ignored because of its high price under our assumptions. Greater price sensitivity increases gasoline's market share to $47 \%$.

M85 also gains but only because Alcohol FVs gain market share. At the higher price elasticity, FFVs choose gasoline all of the time. At lower price elasticities fuel shares tend to be more evenly distributed. Gasoline is still dominant at nearly $40 \%$ of the market, followed by LPG (26\%), M85 (20\%) and CNG (13\%). Electricity gets the same share as its vehicle market share (2\%) and even E85 shows up with a nonzero market share $(0.01 \%)$.

Fuel-type market shares are sensitive to fuel price, as can be seen by comparing fuel shares in conventional gasoline versus reformulated gasoline (RFG) regions. Under the price assumptions used here, RFG costs $\$ 3.78$ more per barrel, or $\$ 0.09$ per gallon. Under the BASE elasticity assumptions, this 9 cent/gallon price increase costs gasoline 15 percentage points in market share (Figure 5.3). Gasoline's loss of market share is almost entirely divided between M85 which gains 11 points and LPG, which gains just under 4 percentage points. CNG picks up less than 1 point and electricity and E85 remain unchanged. 


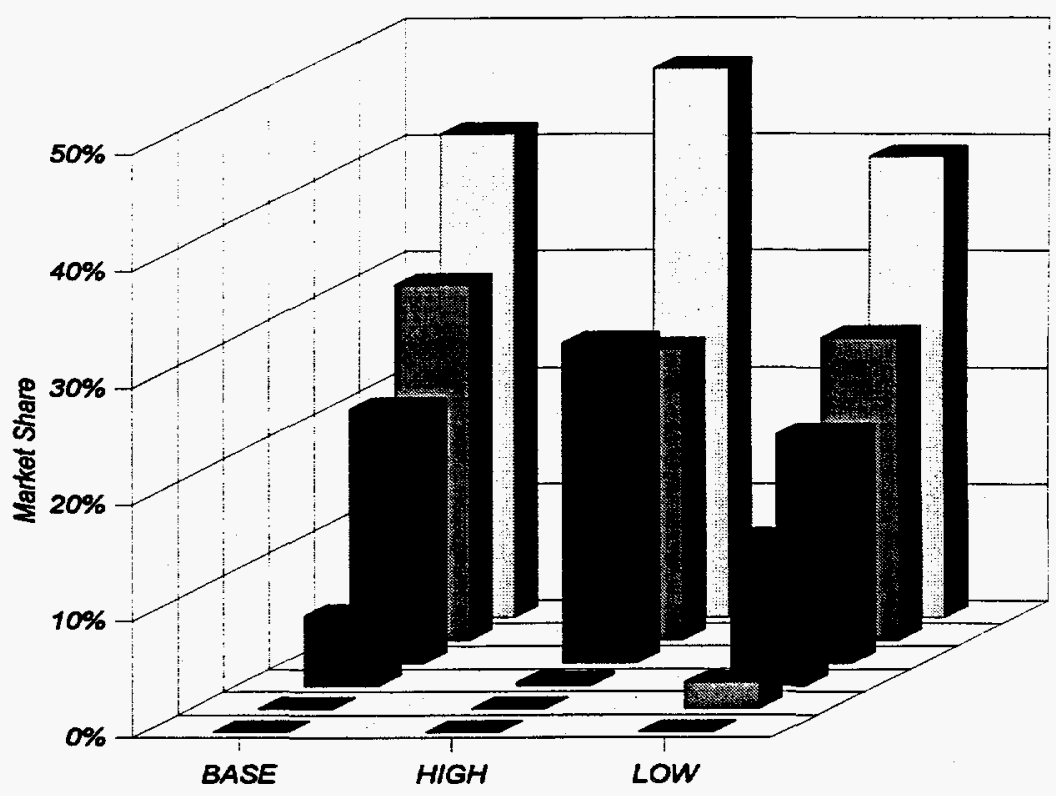

The effect of eliminating the option value for multi-fuel vehicles is also illustrated in Figure 5.3. The option value describes the expected benefit to the owner of a multi-fuel vehicle of being able to buy the least expensive fuel as fuel prices fluctuate. In a static equilibrium model fuel prices are constant, but in reality they fluctuate and the option value is an attempt to capture the effect on demand for multi-fuel vehicles. As figure 5.3 illustrates, however, the effect is minimal. Only the market share of gasoline changes by more than 1 percentage point. The effect on vehicle-type market shares (not shown) is also minor, the largest effect being a gain of $2 \%$ by FFVs.

Finally, the sensitivity of market shares to assumptions about the value of vehicle attributes (hedonic values) was explored. HIGH and LOW cases were constructed using the attribute values and time values shown in Table 5.3. The HIGH case doubles the value of cargo space, triples the value of performance, increases the value of time spent refueling electric vehicles by a factor of five and doubles the value of time spent refueling other vehicle types. The LOW case cuts all the BASE values in half. 
Figure 5.3 Fuel Type Market Shares
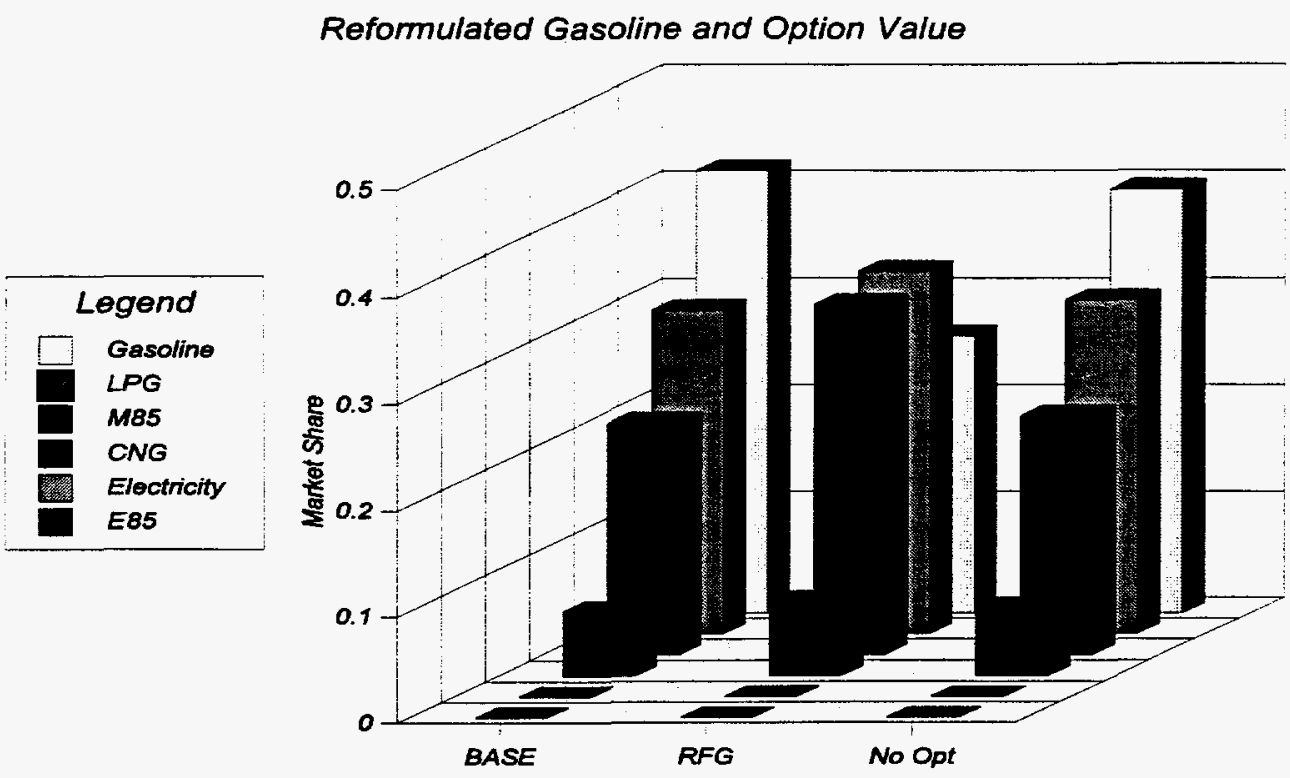

Table 5.3 Alternate Values for Vehicle Attributes and Refueling Time

\begin{tabular}{|l|r|r|r|}
\hline & \multicolumn{1}{|c|}{ BASE } & \multicolumn{1}{c|}{ HIGH } & \multicolumn{1}{c|}{ LOW } \\
\hline Value of cubic foot of cargo space & $\$ 25.00$ & $\$ 50.00$ & $\$ 12.50$ \\
\hline Value of 1\% change in H.P./weight. ratio & $\$ 25.00$ & $\$ 75.00$ & $\$ 12.50$ \\
\hline Value of 1 hour refueling & $\$ 10.00$ & $\$ 20.00$ & $\$ 5.00$ \\
\hline Value of 1 hour refueling battery electric & $\$ 1.00$ & $\$ 5.00$ & $\$ 0.50$ \\
\hline
\end{tabular}

The principal effect of increasing the hedonic values of attributes is to shift sales toward alcohol vehicles, particularly the alcohol flexible vehicle which moves up to $27 \%$ from $20 \%$ (Figure 5.4 ). The chief reason is its improved performance. Conventional gasoline vehicles also gain slightly In general, gaseous fueled vehicles lose because their performance tends to be lower and because of the loss of cargo space to bulkier fuel storage tanks. Cutting hedonic values in half, on the other hand, has relatively small impacts across the board. Alcohol FVs, FFVs, and conventional gasoline vehicles each lose about 1 point, dedicated LPG vehicles remain the same and the other three types of gaseous-fueled vehicles gain about 1 point. Relatively speaking, the biggest winner is the EV whose share increases from $0.03 \%$ to $0.19 \%$. Apparently the BASE hedonic value levels, together 
with the assumed vehicle attributes, make characteristics relatively less important in determining vehicle market shares than purchase prices and fuel prices.

This sensitivity analysis has explored the effects of alternative assumptions about AFVC model parameters in a relatively wide range about the BASE values. Although the predicted market shares for vehicles and fuels are sensitive to changing parameter values, none of the changes tested here altered the basic structure of market demand for alternative fuels and vehicles. That structure is primarily determined by fuel prices together with assumptions about initial vehicle costs and objective vehicle attributes. Increasing elasticities of vehicle and fuel demand did tend to shift demand toward the more successful fuels: alcohol, gasoline, and LPG. Reducing elasticities tends to distribute demand more evenly across all vehicle and fuel options. Increasing the value of performance favors the high-performing alcohol-fueled vehicles, and increasing the value of time favors all liquid fueled vehicles and LPG (which is stored on-board in liquid phase). Market shares are sensitive to price, which means that AFVs do substantially better against RFG than conventional gasoline. Although the results of this sensitivity analysis suggest a certain degree of robustness in the AFVC model predictions, ultimately those predictions are entirely dependent on the reasonableness of assumed vehicle characteristics and fuel prices.

Figure 5.4 Vehicle Type Market Shares

Sensitivity to Hedonic Values
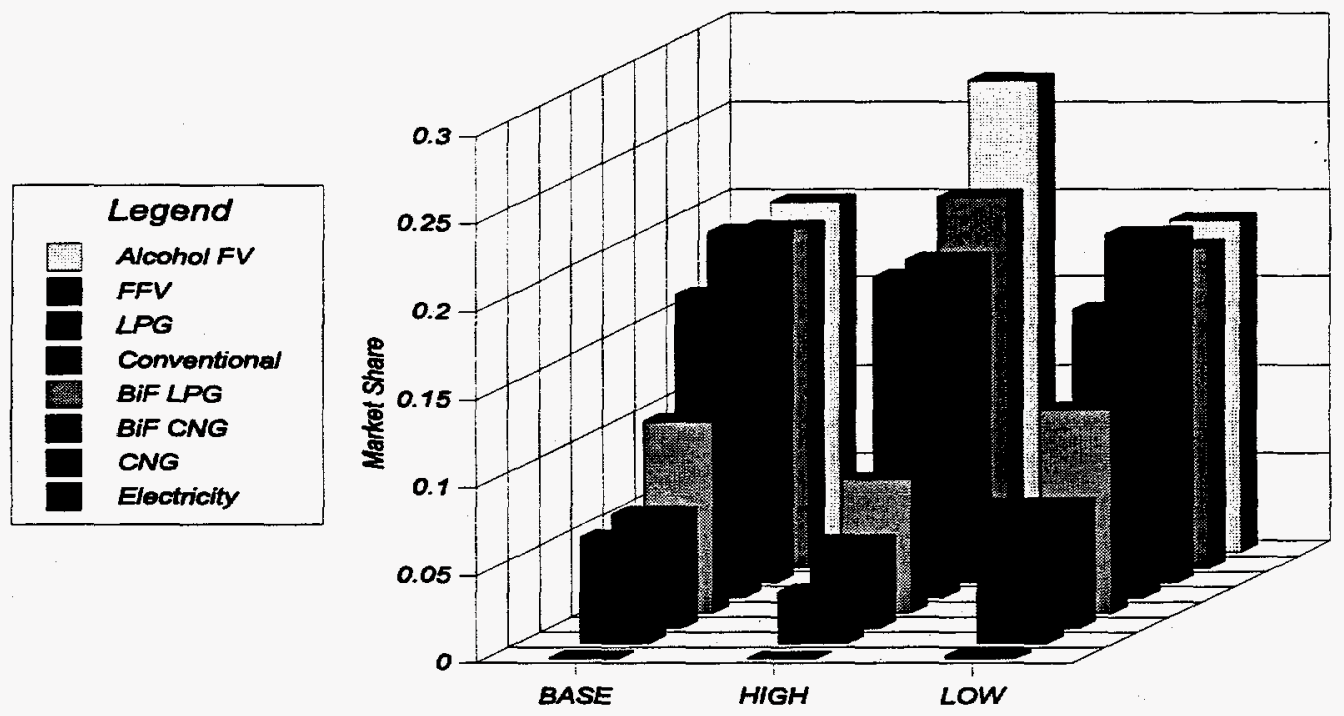


\section{REFERENCES}

1. Amemiya, T. (1985). Advanced Econometrics, Harvard University Press, Cambridge, Massachusetts.

2. Anderson, S. P., A. De Palma, and J. F. Thisse. (1988). "A Representative Consumer Theory of the Logit Model," International Economic Review, vol. 29, no. 3, pp. 461-466, August.

3. Bechtold, R. L. (1993a). "AFV Differential Costs," technical memorandum, EA Engineering, Science, and Technology, Inc., Silver Spring, Maryland, September 13, 1993.

4. Bechtold, R. L. (1993b). "Light Duty Vehicle Queueing Analysis for Alternative Fuel/Gasoline And Conventional Gasoline Refueling Stations," EA Engineering, Science, and Technology, Inc., Silver Spring, Maryland, August, 30, 1993.

5. Bechtold, R. (1993c). "CNG Vehicle Loss of Trunk Volume," personal communication to D. Greene of Oak Ridge National Laboratory, from EA Engineering, Science, and Technology, Inc., Silver Spring, Maryland, February 21, 1993.

6. Beggs, S. D., and N. S. Cardell. (1980). "Choice of Smallest Car by Multi-Vehicle Households and the Demand for Electric Vehicles," Transportation Research A, Vol. 14A, no. 5-6, pp. 389-404.

7. Ben-Akiva, M. and S. R. Lerman. (1987). Discrete Choice Analysis: Theory and Applications to Travel Demand, MIT Press, Cambridge, Massachusetts.

8. Bunch, D. S., M. Bradley, T. F. Golob, R. Kitamura, and G. P. Occhiuzzo. (1993). "Demand for Clean-Fuel Vehicles in California: a Discrete-Choice State Preference Pilot Project," Transportation Research A, vol. 27A, no. 3, pp. 237-254.

9. Charles River Associates, Inc. (1981). "The Demand for Electric Automobiles," EPRI EA 2072, Project 1145-1 Final Report to Electric Power Research Institute, Palo Alto, California.

10. Chui, M. K. and W. F. McFarland. (1986). "The Value of Travel Time: New Estimates Developed Using a Speed Choice Model," TT1:2-8-84-396-2F, Texas Transportation Institute, The Texas A \& M University System, College Station, Texas, May.

11. Davis, S. C. and S. G. Strang. (1993). Transportation Energy Data Book: 13, ORNL-6743, Center for Transportation Analysis, Oak Ridge National Laboratory, Oak Ridge, Tennessee, March.

12. DeLuchi, M. A., Q. Wang, and D. Sperling. (1989). "Electric Vehicles: Performance, LifeCycle Costs, Emissions, and Recharging Requirements," Transportation Research A, Vol. 23-A, No. 3, pp. 255-278, May. 
13. Dougher, R. S., L. A. Hofmann, and T. F. Hogarty. (1990). "Analysis of Factors Influencing the Consumption of Premium Motor Gasolines," Res. Study \#052, American Petroleum Institute, Washington, DC, July.

14. Energy Information Administration, U. S. Department of Energy. (1994). Alternatives to Traditional Transportation Fuels: An Overview, DOE/EIA-0585/O, Washington, DC, June.

15. Energy and Environmental Analysis, Inc. (1987). "Fuel Purchasing Patterns and Vehicle Use Trends From the NPD Research Gasoline Diary Data Base: October 1983 - September 1984 Data Display," Arlington, Virginia, April.

16. Fisk, C. S., and D. Boyce. (1984). "A Modified Composite Cost Measure for Probabilistic Choice Modeling," Environment and Planning A, v. 16, pp. 241-248.

17. Golob, T. F., R. Kitamura, D. S. Bunch, M. Bradley, and J. Golob. (1992). "Clean Vehicles/Fuels Stated Preference Pilot Study: FINAL REPORT," Demand Forecasting Office, California Energy Commission, Sacramento, California.

18. Greene, D. L. (1986). "The Market Share of Diesel Cars in the USA, 1979-83," Energy Economics, vol. 8, no. 1, pp. 13-21, January.

19. Greene, D. L. and J. T. Liu. (1988). "Automotive Fuel Economy and Consumers' Surplus," Transportation Research A, vol. 22A, no. 3, pp. 203-218.

20. Greene, D. L. (1989). "Motor Fuel Choice: An Econometric Analysis," Transportation Research A, vol. 23A, nol. 3, pp. 243-253.

21. Greene, D. L. (1989). "Fuel Choice for Dual-Fuel Vehicles: An Analysis of the Canadian Natural Gas Vehicles Survey," SAE 892067, pp. 25-34, in Gaseous Fuels: Technology, Performance, and Emissions, Society of Automotive Engineers, Warrendale, PA.

22. Interagency Commission on Alternative Motor Fuels. (1990). "First Interim Report of the Interagency Commission on Alternative Motor Fuels," Office of Energy Demand Policy, Office of Domestic and International Energy Policy, U.S. Department of Energy, Washington, DC, September.

23. Interagency Commission on Alternative Motor Fuels. (1991). "Second Interim Report," Office of Energy Demand Policy, Office of Domestic and International Energy Policy, U. S. Department of Energy, Washington, DC, September.

24. Johnson, N. L. and S. Kotz. (1970). Continuous Univariate Distributions Volume 1, Houghton Mifflin \& Company, Boston.

25. Kurani, K. (1993). "Fuel Availability, Dual Fuel Vehicles and Learning in New Zealand," paper presented at the $72^{\text {nd }}$ Annual Meeting of the Transportation Research Board, Washington, DC, January. 
26. Kurani, K. S. and D. Sperling. (1988). "Rise and Fall of Diesel Cars: A Consumer Choice Analysis," Transportation Research Record 1175, Transportation Research Board, Washington, DC.

27. Lancaster, K. J. (1966). "A New Approach to Consumer Theory," Journal of Political Economy, Vol. 74, No. 2, pp. 132-157, April.

28. Lave, C. A. and K. Train. (1979). A Disaggregate Model of Autotype Choice." Transportation Research, vol. 13A, 1-9.

29. Leiby, P. N. (1993). "A Methodology for Assessing the Market Benefits of Alternative Motor Fuels," ORNL-6771, Oak Ridge National Laboratory, Oak Ridge, Tennessee, September.

30. Leiby, P. N. and D. L. Greene. (1993). "Including Sharing Functions in an Optimization Framework: The Multinomial Logit Case," draft memorandum, Energy Division, Oak Ridge National Laboratory, Oak Ridge, Tennessee, February 22, 1993.

31. Maddala, G. S. (1992). Limited-Dependent and Qualitative Variables in Econometrics, Cambridge University Press, Cambridge.

32. Manne, A. (1989). "Alternative Fuels Trade Model," memorandum to the U. S. Department of Energy, Office of Energy Demand Policy, from Alan Manne, Stanford University, Palo Alto, California.

33. Manski, C. F. and L. Sherman. (1980). "An Empirical Analysis of Household Choice among Motor Vehicles," Transportation Research A, vol. 14A, nos. 5-6, pp. 349-366.

McCarthy, P. S. and R. Tay. (1989). "Consumer Valuation of New Car Attributes: An Econometric Analysis of the Demand for Domestic and Japanese/Western European Imports," Transportation Research, vol. 23A, No. 5.

34. McFadden, D. (1974). "Conditional Logit Analysis of Qualitative Choice Behavior", in Frontiers in Econometrics, pp. 105-142 in P. Zarembka, ed., Academic Press, New York.

35. McNutt, B. (1993). Memorandum entitled, "Alternative Fuel Vehicle Fuel Economy Estimates," U.S. Department of Energy, Office of Energy Demand Policy, Washington, D.C., August, 1993.

36. Murrell, J. D. (1980). "Passenger Car Fuel Economy: EPA and Road," EPA 460/3-80-010, U.S. Environmental Protection Agency, Motor Vehicle Emission Lab, Ann Arbor, Michigan, September.

37. Murrell, J. D., K. H. Hellman, and R. M. Heavenrich. (1993). "Technical Report: LightDuty Automotive Technology and Fuel Economy Trends Through 1993," EPA/AA/TDG/9301, U.S. Environmental Protection Agency, Emission Control Technology Division, Ann Arbor, Michigan, May. 
38. Phillips, O. R., and D. P. Schutte. (1988). "Identifying Profitable Self-Service Markets: a Test in Gasoline Retailing," Applied Economics, vol. 20, pp. 263-272.

39. Setiawan, W., D. Hungerford, and D. Sperling. (1990). "Premium Gasoline and Methanol: A Consumer Choice Analysis," mimeo, Transportation Research Group, University of California at Davis, Davis, California, June.

40. Society of Automotive Engineers. (1992). "Battery and Electric Vehicle Update," Automotive Engineering, vol. 100, no. 9, pp. 17-25, September.

41. Sperling, D. and K. S. Kurani. (1987). "Refueling and the Vehicle Purchase Decision: The Diesel Car Case," SAE 870644, Society of Automotive Engineers, Warrendale, PA.

42. Sperling, D., D. Hungerford, and K. Kurani. (1990). "Consumer Demand for Methanol," pp. 359-377, in W. L. Kohl, Ed., Methanol as an Alternative Fuel Choice: An Assessment, School of Advanced International Studies, The Johns Hopkins University, Washington, DC.

43. Train, K. (1980). "The Potential Market for Non-Gasoline-Powered Automobiles," Transportation Research A, vol. 14A, no. 5-6, pp. 405-414.

44. Train, K. and M. Lohrer. (1982). "Vehicle Ownership and Usage: An Integrated System of Disaggregate Demand Models," report prepared for the California Energy Commission by Cambridge Systematics, Inc., Berkeley, California, March 31, 1982.

45. Train, K. (1986). Qualitative Choice Analysis, MIT Press, Cambridge, Massachusetts.

U. S. Department of Energy. (1988). "Assessment of Costs and Benefits of Flexible and Alternative Fuel Use in the U.S. Transportation Sector," U. S. Government Printing Office, Washington, DC, January.

46. U. S. Congress, House of Representatives, "Energy Policy Act of 1992, Conference Report 102-1018 to Accompany H. R. 776," U. S. Government Printing Office, Washington, DC, October 5 .

47. U. S. Department of Energy, Energy Information Administration. (1993). "Household Vehicles Energy Consumption 1991," DOE/EIA-0464(91), Washington, DC, December.

48. U. S. Department of Energy, Energy Information Administration. (1993). "Annual Energy Outlook 1993," DOE/EIA-0383(93), Washington, DC, January.

49. Wang, Q., D. Sperling, J. Olmstead. (1993). "Emission Control Cost-Effectiveness of Alternative-Fuel Vehicles," Institute of Transportation Studies, University of California, Davis, California.

50. Williams, H. C. W. L. (1974). "On the Formation of Travel Demand Models and the Evaluation of User Benefit," Environment and Planning A, vol. 9, pp. 285-344. 


\section{APPENDIX A}

\section{DERIVATION OF MULTINOMIAL LOGIT MODEL}

We wish to show that if the utility of option $i$ is defined as $U_{i}=V_{i}+\epsilon_{i}=V\left(X_{i}\right)+\epsilon_{i}$, where $X_{i}$ is a vector of known attributes and $\epsilon_{i}$ is a random error term having the type 1 extreme value distribution (Johnson and Kotz, 1970) with cumulative density function, ${ }^{24}$

$$
F\left(\epsilon_{i}<\epsilon\right)=\exp \left(-e^{-\beta \epsilon}\right)
$$

and probability density function,

$$
f\left(\epsilon_{i}\right)=\beta \exp \left(-\beta \epsilon_{i}-e^{-\beta \epsilon_{i}}\right)
$$

then the probability that $U_{i}=\operatorname{Max}\left(U_{1}, U_{2}, U_{3}, \ldots U_{M}\right)$, that is, that has the $i^{\text {th }}$ choice has the highest utility of all $M$ possible choices, given the vectors $X_{j},(j=1, M)$, is given by,

$$
\operatorname{Prob}\left(U_{i}=\operatorname{Max}\left[U_{j} \forall j\right]\right)=\frac{e^{\beta V_{i}}}{\sum_{j=i}^{M} e^{\beta V_{j}}}
$$

The condition $\mathrm{U}_{\mathrm{i}}=\operatorname{Max}\left(\mathrm{U}_{1}, \mathrm{U}_{2}, \mathrm{U}_{3}, \ldots \mathrm{U}_{\mathrm{M}}\right)$, implies,

$$
\epsilon_{j}<\epsilon_{i}+V_{i}-V_{j} \quad, \forall j \neq i
$$

and the probability of this is given by,

$$
\operatorname{Prob}\left(\epsilon_{j}<\epsilon_{i}+V_{i}-V_{j}\right)=\int_{-\infty}^{\infty} \prod_{j \neq i} F\left(\epsilon_{i}+V_{i}-V_{j}\right) \cdot f\left(\epsilon_{i}\right) d \epsilon_{i}
$$

Substituting the appropriate cumulative and probability density functions this becomes,

$$
\operatorname{Prob}\left(U_{i}=M a x\right)=\int_{-\infty}^{\infty} \prod_{j \neq i} \exp \left(-e^{-\beta\left(\epsilon_{i} \cdot v_{i}-v_{j}\right)}\right) \cdot \beta \exp \left(-\beta \epsilon_{i}-e^{-\beta \epsilon_{i}}\right) d \epsilon_{i}
$$

\footnotetext{
${ }^{24}$ This exposition follows that of Maddala (1992) pp. 60-61.
} 
Carrying out the multiplication within the product symbol we get,

$$
=\int_{-\infty}^{\infty} \exp \left(-e^{-\beta \epsilon_{i}} \sum_{j \neq i} e^{-\beta V_{i} \cdot \beta V_{j}}\right) \cdot \beta \exp \left(-\beta \epsilon_{i}-e^{-\beta \epsilon_{i}}\right) d \epsilon_{i}
$$

Rearranging terms gives,

$$
=\int_{-\infty}^{\infty} \beta \exp \left(-\beta \epsilon_{i} e^{-\beta \epsilon_{i}}\left[1+\sum_{j \neq i} e^{-\beta V_{i} \cdot \beta V_{j}}\right]\right) d \epsilon_{i}
$$

if we make the substitution,

$$
\lambda_{i}=\log \left(1+\sum_{j \neq i} \frac{e^{\beta V_{j}}}{e^{\beta V_{i}}}\right)=\log \left(\sum_{j=1}^{M} \frac{e^{\beta V_{j}}}{e^{\beta V_{i}}}\right)
$$

we get a much simplified integral,

$$
\operatorname{Prob}\left(U_{i}=M a x\right)=\int_{-\infty}^{\infty} \beta \exp \left(-\beta \epsilon_{i}-e^{-\beta\left(\epsilon_{i}-\lambda_{i}\right)}\right) d \epsilon_{i}
$$

which can be further simplified by making the additional substitution $\epsilon_{i}^{*}=\epsilon_{i}-\lambda_{i}$, and noting that the integral of a probability density function is equal to 1 .

$$
=\exp \left(-\lambda_{i}\right) \int_{-\infty}^{\infty} \beta \exp \left(-\beta \epsilon_{i}^{\cdot}-e^{-\beta \epsilon_{i}^{*}}\right) d \epsilon_{i}^{*}=\exp \left(-\lambda_{i}\right)=\frac{e^{\beta V_{i}}}{\sum_{j=1}^{M} e^{\beta V_{j}}}
$$

This derivation is extremely important because it shows that the coefficient of the function $V\left(X_{i}\right)$ is precisely the scale parameter of the random error's probability density function. Note that this is true regardless of the units in which $V_{i}$ is expressed since these are taken into account by the units in which $\beta$ is expressed. Therefore, if we choose $V_{i}$ to be a generalized cost function, enumerated in dollars, the coefficient of price in $V_{i}$ equals $\beta$. This result is useful because it allows us to precisely specify the logsum term in the nested logit model, based on knowledge of the price coefficients of the choice subsets (nests). 